\title{
Quantum dots as targeted doxorubicin drug delivery nanosystems in human lung cancer cells
}

\author{
Monika Ruzycka-Ayoush ${ }^{1 *} \mathbb{0}$, Patrycja Kowalik2,3, Agata Kowalczyk², Piotr Bujak³, Anna M. Nowicka², \\ Maria Wojewodzka ${ }^{4}$, Marcin Kruszewski ${ }^{4,5}$ and Ireneusz P. Grudzinski ${ }^{1}$
}

${ }^{*}$ Correspondence: mruzycka@wum.edu.pl

${ }^{1}$ Faculty of Pharmacy, Medical University of Warsaw, Banacha 1, 02-097 Warsaw, Poland

Full list of author information is available at the end of the article

\begin{abstract}
Background: Lung cancer is one of the most frequently diagnosed cancers all over the world and is also one of the leading causes of cancer-related mortality. The main treatment option for small cell lung cancer, conventional chemotherapy, is characterized by a lack of specificity, resulting in severe adverse effects. Therefore, this study aimed at developing a new targeted drug delivery (TDD) system based on Ag-In$\mathrm{Zn}-\mathrm{S}$ quantum dots (QDs). For this purpose, the QD nanocrystals were modified with 11-mercaptoundecanoic acid (MUA), L-cysteine, and lipoic acid decorated with folic acid (FA) and used as a novel TDD system for targeting doxorubicin (DOX) to folate receptors (FARs) on adenocarcinomic human alveolar basal epithelial cells (A549). $\mathrm{NIH} / 3 \mathrm{~T} 3$ cells were used as FAR-negative controls. Comprehensive physicochemical, cytotoxicity, and genotoxicity studies were performed to characterize the developed novel TDDs.
\end{abstract}

Results: Fourier transformation infrared spectroscopy, dynamic light scattering, and fluorescence quenching confirmed the successful attachment of FA to the QD nanocrystals and of DOX to the QD-FA nanocarriers. UV-Vis analysis helped in determining the amount of FA and DOX covalently anchored to the surface of the QD nanocrystals. Biological screening revealed that the QD-FA-DOX nanoconjugates had higher cytotoxicity in comparison to the other forms of synthesized QD samples, suggesting the cytotoxic effect of DOX liberated from the QD constructs. Contrary to the QD-MUA-FA-DOX nanoconjugates which occurred to be the most cytotoxic against A549 cells among others, no such effect was observed for $\mathrm{NIH} / 3 \mathrm{~T} 3$ cells, confirming FARs as molecular targets. In vitro scratch assay also revealed significant inhibition of A549 cell migration after treatment with QD-MUA-FA-DOX. The performed studies evidenced that at $I_{50}$ all the nanoconjugates induced significantly more DNA breaks than that observed in nontreated cells. Overall, the QD-MUA-FA-DOX nanoconjugates showed the greatest cytotoxicity and genotoxicity, while significantly inhibiting the migratory potential of A549 cells.

Conclusion: QD-MUA-FA-DOX nanoconjugates can thus be considered as a potential drug delivery system for the effective treatment of adenocarcinomic human alveolar basal epithelial cells.

Keywords: Quantum dots, Doxorubicin, Targeted drug delivery, Lung cancer cells, Nanochemistry, Cytotoxicity, Genotoxicity 


\section{Background}

Lung cancer is the second most common form of cancer in both men and women in the Western world. The most frequent subtype of lung cancer is non-small cell lung cancer (84\%) (American Cancer Society 2020). According to the predictions of the American Cancer Society, lung and bronchial cancers will account for approximately $13 \%$ of all the newly diagnosed cancers and for approximately $22 \%$ of all cancer deaths, thus becoming the leading cause of cancer-related mortalities in the United States in 2020 (American Cancer Society 2020; Siegel et al. 2020). It is estimated that in the European Union, the incidence of lung cancers will be also high, accounting for about $12 \%$ of the total cancer incidences in 2020. Moreover, lung cancers will account for approximately $20 \%$ of all cancer deaths, with cancer-related mortality being higher among men (ECIS 2020). Unfortunately, the 5-year survival rate for all types of lung cancer is extremely low (19\%), which reflects that a high percentage of patients are diagnosed with metastatic disease (5-year relative survival rate of 5\%) (Siegel et al. 2020). Although there are many treatment possibilities for lung cancer including surgery, chemotherapy, and radiotherapy, survival mainly depends on the type and stage of cancer. The main treatment option, conventional chemotherapy, is limited by a lack of specificity, resulting in high general toxicity (Yuan et al. 2019). It is believed that nanotechnology-based strategies can significantly improve the response of lung cancer cells to common chemotherapeutics and reduce drug toxicity by selectively docking at cancer sites and metastases.

The dynamic development of nanotechnology has opened new possibilities for using nanoscaled materials in innovative therapies and diagnostics in modern nanomedicine. Among the different nanoparticles studied in the biomedical sector, metal and metal oxides, dendrimers, and silica- and carbon-based nanoparticles, especially quantum dots (QDs), have been vigorously tested as novel theranostics (Ha et al. 2019). QDs are fascinating nanoscale semiconductor crystals, which are gaining increasing attention in nanomedicine due to their unique physical and optical properties. Their advantages include a small diameter ranging from 2 to $100 \mathrm{~nm}$ (Peynshaert et al. 2017), size-tunable light emission (Matea et al. 2017), wide absorption/extinction coefficients, and high fluorescent quantum yields (Abbasi et al. 2016). The surface composition of QDs may be chemically modified to alter their emission spectra (Peynshaert et al. 2017) or enhance their water solubility (Bilan et al. 2015) and biocompatibility (Peynshaert et al. 2017). It has been reported that the optical properties of graphene QDs were improved by doping nonmetallic atoms such as potassium, nitrogen, sulfur, chlorine, fluorine, and selenium (Qian et al. 2016) or surface functionalization with functional groups such as alcohol, amine, thiol (Qian et al. 2013), or alkyl (Peynshaert et al. 2017). In addition, the coating of graphene QDs with polyethylenimine of different molecular weights was observed to enhance the photoluminescence intensity (Peynshaert et al. 2017). Covalent functionalization of silicon QDs with phenanthrene, pyrene, and perylene chromophores (Abdelhameed et al. 2018) effectively tuned the emission color as well as enhanced the emission quantum efficiency. In order to enhance their water solubility and thus biocompatibility, QDs can be coated with hydrophilic ligands (such as thiolate alcohols, thiolate acids and thiolate siloxane acids (Zhou et al. 2017), or monothiol ligands including 3-mercaptopropionic acid (MPA) (Ali et al. 2019) and mercaptoundecanoic (MUA)), amphiphilic polymers (such as polyethylene glycol (Susumu et al. 2009), poly(N-isopropylacrylamide) 
(Hu and Gao 2010)), or silica (Cao et al. 2020; Hu and Gao 2010). Besides these, glutathione (Aydemir et al. 2020), bovine serum albumin (Barba-Vicente et al. 2020; Sahoo et al. 2019), poly(lactic-co-glycolic acids), and chitosan (Kharkar et al. 2020) were also reported to promote the biocompatibility of QDs.

Versatile functionalization of QDs with biomolecules [such as antibodies (Qiu et al. 2014)] and/or drugs makes them attractive nanoplatforms for application in diagnostics (imaging or sensing) (Matea et al. 2017) as well as therapy, depending on their ability of site-specific drug delivery to organs (Hardman et al. 2006), cells, and even cell components (Wegner et al. 2015). Moreover, QDs are recognized as a powerful tool for simultaneous application in diagnosis and treatment, as they have a great potential for concurrent use in biosensing, imaging, and therapy as nanotheranostic platforms (Matea et al. 2017).

The recently developed cancer-targeted treatment has immense efficiency due to the selective distribution of the drug at the tumor site at therapeutically effective concentrations along with lowering systemic toxicity and therapeutic index (Salahuddin et al. 2017). The site-specific therapeutic delivery is possible with the use of nanoscaled materials, like QDs, which can be functionalized with self-navigating elements and therapeutic cargo. Folic acid (FA) has the ability of selective self-navigation, as folate receptors (FARs) are frequently overexpressed on the surface of some human cancer cells. FA can be easily and nondestructively internalized into cancerous cells via the endocytic pathway that facilitates the delivery of folate-conjugated anticancer drug payloads into cells by the same receptor-mediated process called Trojan horse strategy (Patel et al. 2018; Sosnik et al. 2018; Zhang et al. 2018). Treatments involving folate-targeted approaches were extensively studied in the context of different therapeutic cargos, including chemotherapeutic agents, imaging agents, oligonucleotides, and DNA molecules (Kumar et al. 2019). One of the widely used chemotherapeutic agents is doxorubicin (DOX), a topoisomerase inhibitor whose interaction with DNA leads to the suppression of cancer cell growth (Kumar et al. 2017). DOX is useful for treating various types of cancer, including lung (Hong et al. 2019), breast (Lovitt et al. 2018), colon (Lin et al. 2018), and hematologic cancers (Au et al. 2019). Although many studies have reported successful treatment and attenuation of cancers with the use of DOX, its frequent clinical application induces multidrug resistance (MDR) and severe side effects including cardiotoxicity and ototoxicity, as well as liver abnormalities, increase in the blood level of uric acid, and heart failure. To overcome these adverse effects, it was proposed that DOX should be encapsulated and/or chemically conjugated to nanoparticles (Gu et al. 2012). This paper describes the development of Ag-In-Zn-S QDs conjugated with FA and DOX for the treatment of adenocarcinomic human alveolar basal epithelial cells (A549). For further functionalization of QDs with FA and DOX, their surface was modified with MUA, L-cysteine (Cys), and lipoic acid (LA) ligands. This resulted in nine compounds, including QD-MUA, QD-Cys, and QD-LA nanocrystals; QD-MUA-FA, QD-Cys-FA, and QD-LA-FA nanocarriers; and QD-MUA-FA-DOX, QD-Cys-FA-DOX, and QDLA-FA-DOX nanoconjugates. The physicochemical characterization of the synthesized QDs was performed using transmission electron microscopy (TEM), Fourier transformation infrared (FTIR) spectroscopy, fluorescence spectroscopy, UV-Vis spectroscopy, dynamic light scattering (DLS), and zeta potential (ZP) analysis. The basic cytotoxic 
effect of QDs was evaluated using Alamar Blue and colony forming efficiency (CFE) assays. NIH/3T3 cells were used as FAR-negative controls. The migratory potential of A549 cells exposed to the newly synthesized QDs was estimated using in vitro wound healing assay (scratch assay). Genotoxicity, which was expressed as the induction of DNA breaks, was assessed using the single-cell gel electrophoresis assay (comet assay).

\section{Materials and methods}

Materials

Sodium dihydrogen phosphate, disodium hydrogen phosphate, sodium chloride, potassium chloride (all from POCH, Poland), silver nitrate (99\%), indium(III) chloride (98\%), zinc stearate (technical grade), 1-dodecanethiol (DDT, 98\%), sulfur (99\%), 1-octadecene (ODE, 90\%), oleylamine (OLA, 70\%), MUA (95\%), dimethyl sulfoxide (DMSO), Cys (>97\%), LA (>99\%), $N$-hydroxy-succinimide (NHS), $N$-(3-dimethylaminopropyl)- $N^{\prime}$ ethylcarbodiimide hydrochloride (EDC), DOX hydrochloride, and FA $(>97 \%)$ were all purchased from Sigma-Aldrich, USA. Reagents and chemicals used in the nanoconjugate synthesis and cytotoxicity tests were of the highest purity available and used as received.

\section{Synthesis of Ag-In-Zn-S nanocrystals}

The synthesis of Ag-In-Zn-S nanocrystals (QDs) and primary ligand exchange procedures were performed following the earlier literature descriptions (Gabka et al. 2014, 2017). All operations were conducted under a constant dry argon flow. Silver nitrate (0.03 g, $0.17 \mathrm{mmol})$, indium(III) chloride $(0.13 \mathrm{~g}, 0.59 \mathrm{mmol})$, zinc stearate $(0.87 \mathrm{~g}$, $1.37 \mathrm{mmol}$ for $\left.\mathrm{QD}_{\text {green }}\right)$, and DDT $(0.20 \mathrm{~g}, 1.00 \mathrm{mmol})$ were mixed with ODE (15 mL) in a three-neck flask. The prepared mixture was heated to $150{ }^{\circ} \mathrm{C}$ until a homogenous solution was formed. Then, sulfur $(0.015 \mathrm{~g}, 0.47 \mathrm{mmol})$ dissolved in $1 \mathrm{~mL}$ of OLA was quickly injected into the reaction solution. The temperature of the mixture was increased to $180{ }^{\circ} \mathrm{C}$ and was maintained for $60 \mathrm{~min}$. Then, the mixture was cooled to room temperature and toluene $(20 \mathrm{~mL})$ was added. Further, the mixture was centrifuged and the resulting black precipitate was separated. The collected supernatant was treated with $30 \mathrm{~mL}$ of acetone, and the desired fraction of nanocrystals was obtained as a precipitate. The nanocrystals were separated by centrifugation (7000 rpm, $5 \mathrm{~min}$ ) and then redispersed in toluene.

\section{Ligand exchange for 11-mercaptoundecanoic acid}

A mixture of MUA $(0.5 \mathrm{~g}, 2.3 \mathrm{mmol})$ and $\mathrm{NaOH}(0.1 \mathrm{~g}, 2.5 \mathrm{mmol})$ in water $(10 \mathrm{~mL})$ was prepared under stirring and heated at $50{ }^{\circ} \mathrm{C}$ until a homogenous solution was formed. Then, a toluene dispersion $(10 \mathrm{~mL})$ of nanocrystals was prepared as described above and was injected into this solution. The as-obtained two-phase mixture was heated at $80{ }^{\circ} \mathrm{C}$ for $8 \mathrm{~h}$ under argon atmosphere. After cooling, the reaction mixture was centrifuged for complete phase separation and the solid and organic phases thus obtained were discarded. The remaining water phase was mixed with $20 \mathrm{~mL}$ of acetone, which led to the precipitation of nanocrystals. After centrifugation, the nanocrystals were redispersed in $10 \mathrm{~mL}$ of water. 


\section{Ligand exchange for L-cysteine}

A mixture of Cys $(3.0 \mathrm{~g}, 24.8 \mathrm{mmol})$ and $\mathrm{NaOH}(1.5 \mathrm{~g}, 37.5 \mathrm{mmol})$ in water $(10 \mathrm{~mL})$ was prepared under stirring and heated at $40{ }^{\circ} \mathrm{C}$ until a homogenous solution was formed. Then, a toluene dispersion $(10 \mathrm{~mL})$ of nanocrystals was prepared as described and was injected into this solution. The resulting two-phase mixture was heated at $40{ }^{\circ} \mathrm{C}$ for $4 \mathrm{~h}$ under argon atmosphere. After cooling, the reaction mixture was centrifuged to achieve complete phase separation, and the organic phase was discarded. Then, the water phase was mixed with $20 \mathrm{~mL}$ of acetone, resulting in the precipitation of nanocrystals. After centrifugation, the nanocrystals were redispersed in $10 \mathrm{~mL}$ of water.

\section{Ligand exchange for lipoic acid}

Sodium borohydride $(0.02 \mathrm{~g}, 0.53 \mathrm{mmol})$ was added to a solution of LA (0.2 g, $0.97 \mathrm{mmol})$ and $\mathrm{NaOH}(0.05 \mathrm{~g}, 1.25 \mathrm{mmol})$ in $10 \mathrm{~mL}$ of water and stirred at $40{ }^{\circ} \mathrm{C}$ under argon atmosphere for $1 \mathrm{~h}$. A toluene dispersion $(10 \mathrm{~mL})$ of nanocrystals was prepared as described above and was injected into this solution. The obtained mixture was stirred at $40{ }^{\circ} \mathrm{C}$ for $4 \mathrm{~h}$ and at room temperature for $8 \mathrm{~h}$. Then, the mixture was centrifuged for complete phase separation and the organic phase was discarded. The remaining water phase was mixed with $20 \mathrm{~mL}$ of acetone, which led to the precipitation of nanocrystals. After centrifugation, the nanocrystals were redispersed in $10 \mathrm{~mL}$ of water. The TEM images obtained for the nanocrystals are presented in Fig. 1a, and the parameters of nanocrystals before and after ligand exchange are shown in Table 1.

\section{Synthesis of QD-FA-DOX nanoconjugates}

FA was attached to the QD nanocrystals via the EDC/NHS coupling reaction, as shown in Scheme 1. Briefly, $5 \mathrm{~mL}$ of QDs $\left(10 \mathrm{mg} \cdot \mathrm{mL}^{-1}\right)$ was diluted with $5 \mathrm{~mL}$ of a solution containing $40 \mathrm{mM}$ EDC and $10 \mathrm{mM}$ NHS, and the resulting solution was stirred for $1 \mathrm{~h}$. An FA $(5 \mathrm{mg} ; 10 \mathrm{~mL})$ solution was prepared separately in phosphate-buffered saline (PBS) with the addition of $1 \%$ DMSO. This prepared solution was added to the flask containing the activated QD nanocrystals. The mixtures in the flask were incubated under stirring overnight in ThermoMixer Eppendorf ${ }^{\circledR}$ at room temperature in dark. Then, the mixtures of each type of QD-FA nanocarriers were dialyzed against distilled water for 5 days to remove the unbound FA. The amount of the unbound FA present in the dialysis supernatant was determined by UV-Vis spectroscopy. The difference in the absorbance of the FA band ( $c a .280 \mathrm{~nm}$ ) between the initial solution and supernatant was determined to calculate the amount of FA attached to the QD nanocrystals.

QD-FA-DOX nanoconjugates were prepared by the conjugation of DOX with the QD-FA nanocarriers via amino groups. Briefly, the NHS/EDC-activated QD-FA nanocarriers were added to a $1 \mathrm{mM}$ solution of DOX in citrate buffer (Scheme 1). The reaction was continued overnight at room temperature. Then, the mixtures of each type of QD-FA-DOX nanoconjugates were dialyzed against distilled water for 5 days to remove the unbound DOX. Finally, the obtained nanoconjugates were diluted with water to achieve a QD concentration of $1 \mathrm{mg} \cdot \mathrm{mL}^{-1}$. The amount of DOX conjugated with the QD-FA nanocarriers was determined using the same procedure applied for 

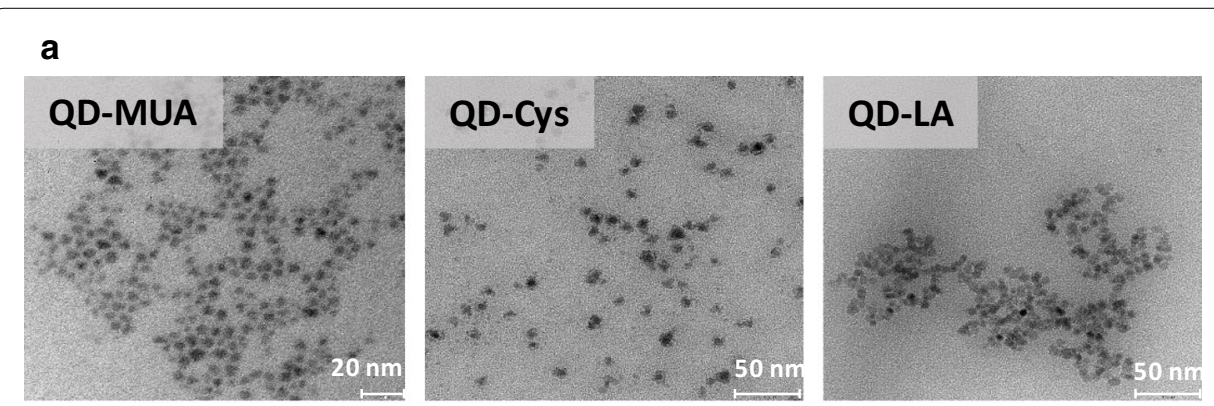

b

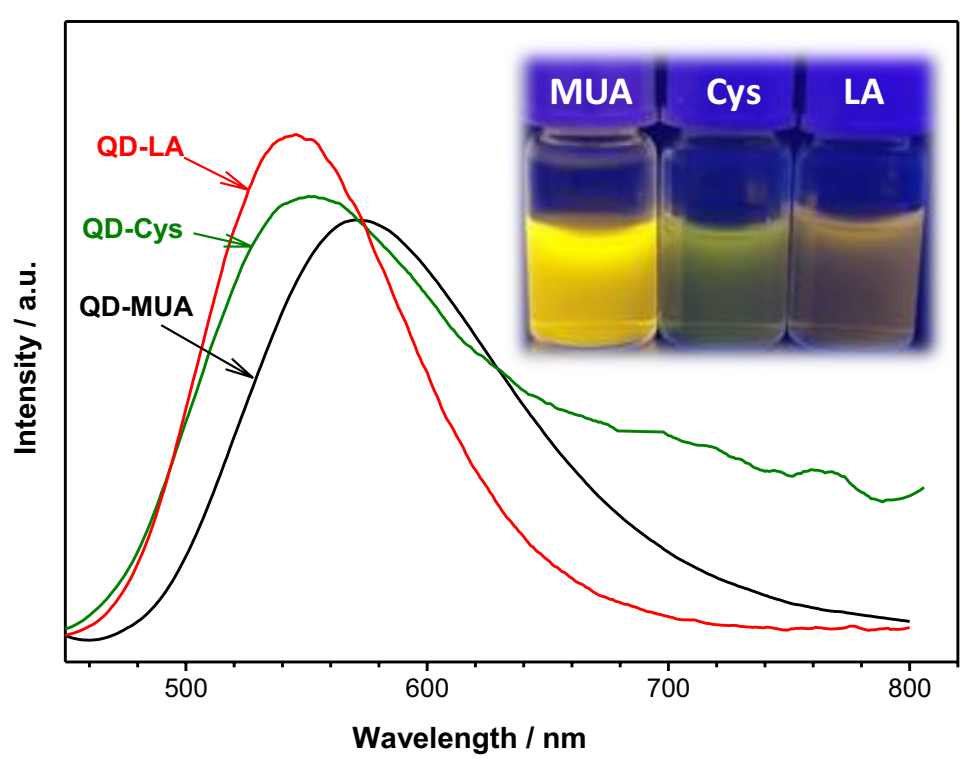

Fig. 1 Transmission electron microscopy images of the QD nanocrystals (a) and their photoluminescence spectra for dispersions in water (b). QD Ag-In-Zn-S nanocrystals modified with: 11-mercaptoundecanoic acid (MUA), Cys L-cysteine, $L A$ lipoic acid. $C_{Q D}=5 \mathrm{mg} \cdot \mathrm{mL}^{-1} ; \lambda_{\text {ex. }}=350 \mathrm{~nm}$; PMT voltage: $700 \mathrm{~V} ;$ PMT integration time: $20 \mathrm{~ms}$; scan speed: $600 \mathrm{~nm} \cdot \mathrm{min}^{-1}$

Table 1 Precursor molar ratios (silver nitrate/indium chloride/zinc stearate/DDT/sulfur in $1 \mathrm{~mL}$ of $\mathrm{OLA}$ ) and characteristics of Ag-In-Zn-S nanocrystals: before and after ligand exchange for MUA, Cys, and LA. TEM was used for size studies

\begin{tabular}{llllll}
\hline Ligand & $\mathbf{A g} / \mathbf{l n} / \mathbf{Z n} / \mathbf{S}_{\mathbf{D D T}} / \mathbf{S}_{\mathbf{s}}$ & $\mathbf{A g} / \mathbf{l n} / \mathbf{Z n} / \mathbf{S}$ & $\begin{array}{l}\mathbf{S i z e}^{\mathbf{a}} \\
\mathbf{( n m})\end{array}$ & $\begin{array}{l}\mathbf{P L}^{\mathbf{b}} \\
(\mathbf{n m})\end{array}$ & $\begin{array}{l}\mathbf{Q . Y}^{\mathbf{c}} \\
\mathbf{( \% )}\end{array}$ \\
\hline Initial ligands & & & $3.2 \pm 0.4$ & 543 & 48.0 \\
MUA & $1.0 / 3.5 / 8.1 / 5.8 / 2.6$ & $1.0 / 1.5 / 7.8 / 17.0$ & $3.1 \pm 0.6$ & 576 & 25.0 \\
Initial ligands & & $1.0 / 1.2 / 5.6 / 9.4$ & $3.2 \pm 0.4$ & 543 & 48.0 \\
Cys & $1.0 / 3.5 / 8.1 / 5.8 / 2.6$ & $1.0 / 1.5 / 7.8 / 17.0$ & $3.1 \pm 1.0$ & 524 & 16.0 \\
Initial ligands & & $1.0 / 6.8 / 14.3 / 154.2$ & $3.2 \pm 0.4$ & 543 & 48.0 \\
LA & $1.0 / 3.5 / 8.1 / 5.8 / 2.6$ & $1.0 / 1.5 / 7.8 / 17.0$ & $3.0 \pm 0.7$ & 540 & 28.0 \\
\hline
\end{tabular}

\footnotetext{
Stearic acid and 1-aminooctadecane

a Average diameter of nanocrystals $(n=200)$ determined by TEM

b PL-maximum of the photoluminescence band

c Q.Y. photoluminescence quantum yield, DDT 1-dodecanethiol, Ss sulfur, MUA 11-mercaptoundecanoic acid, Cys L-cysteine, LA lipoic acid
} 


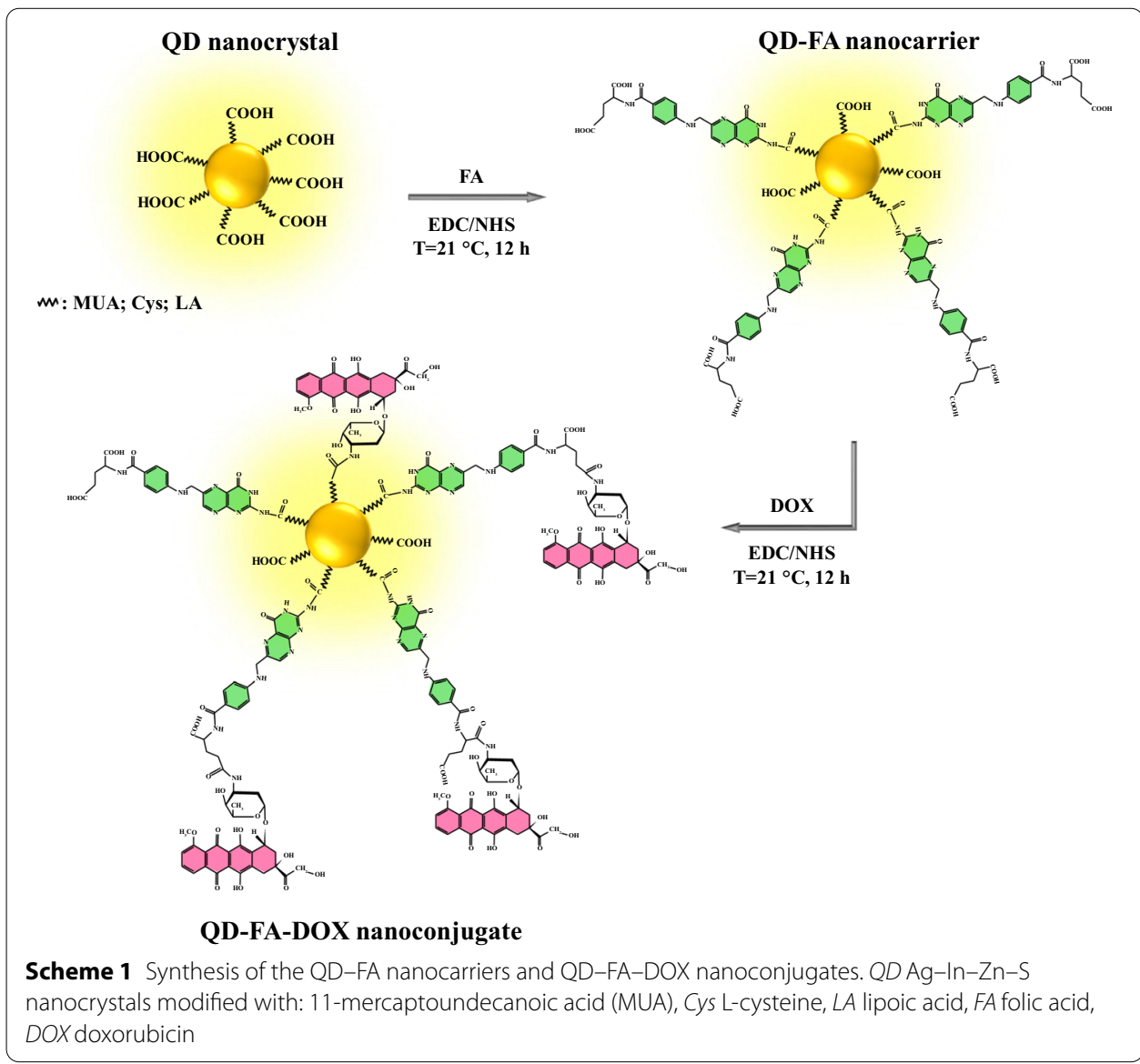

calculating the amount of FA anchored to the QD nanocrystals. From the calculation, it was determined that $c a .400 \mu \mathrm{M}$ of DOX was attached to each type of QD-FA nanocarriers $\left(1 \mathrm{mg} \cdot \mathrm{mL}^{-1}\right)$.

\section{Applied characterization methods}

\section{Transmission electron microscopy (TEM)}

TEM analysis was performed on a Zeiss Libra 120 electron microscope operating at $120 \mathrm{kV}$. The elemental analysis was carried out in a multichannel Quantax 400 EDS system with 125-eV xFlash Detector 5010 (Bruker) using an electron beam of 15-kV energy.

\section{Fourier transformation infrared spectroscopy}

FTIR spectroscopy was used to confirm the successful conjugation of DOX and FA compounds to QDs. For this analysis, pellets were prepared from a mixture of $300 \mathrm{mg}$ of spectrally pure $\mathrm{KBr}$ and $c a .1 .0 \mathrm{mg}$ of the, nanoconjugates (QD-MUA-FA-DOX, QDCys-FA-DOX, and QD-LA-FA-DOX) and pure components (QD-MUA, QD-Cys, 
QD-LA, FA, and DOX). The spectra were acquired in transmission mode on a PerkinElmer System 2000 spectrophotometer at a spectral resolution of $4 \mathrm{~cm}^{-1}$.

\section{Fluorescence spectroscopy}

Fluorometric measurements were performed using a Scinco-FS2 spectrofluorimeter (Scinco, South Korea) in a low-volume $(200 \mu \mathrm{L})$ optical cuvette (product no. 16.100 F/Q/10; Starna Scientific, Co, UK) which was compatible in terms of size and aperture position with the apparatus. The excitation wavelength was adjusted to $350 \mathrm{~nm}$ in compliance with preliminary measurements. The fluorescence spectra were recorded from 360 to $690 \mathrm{~nm}$ with a maximum emission wavelength of $c a$. 535, 550, and $543 \mathrm{~nm}$ for QD-MUA, QD-Cys, and QD-LA, respectively. The other parameters including slit width (excitation: $5 \mathrm{~nm}$, emission: $5 \mathrm{~nm}$ ), PMT voltage $(600 \mathrm{~V})$, and scan speed $\left(600 \mathrm{~nm} \cdot \mathrm{min}^{-1}\right)$ were adjusted experimentally to achieve the best sensitivity and linearity in the respective concentration range of the used compounds.

\section{UV-Vis spectroscopy}

The UV-Vis spectra were obtained with a PerkinElmer spectrometer (model Lambda 25) at a temperature of $21^{\circ} \mathrm{C}$ using a quartz cuvette of 1 -cm length.

\section{Dynamic light scattering and zeta potential analysis}

DLS and ZP measurements were performed using a Zetasizer nano series apparatus (Malvern) with a $\mathrm{He}-\mathrm{Ne}(4 \mathrm{~mW})$ laser at $632.8 \mathrm{~nm}$. The experiments were carried out in buffer at $25^{\circ} \mathrm{C}$, for at least five times, with three freshly prepared samples.

\section{Cell line}

A549 (ATCC $^{\circledR}$ CCL-185 $^{\mathrm{TM}}$ ) and NIH/3T3 $\left(\right.$ ATCC $^{\circledR}$ CCL-1658 $^{\mathrm{TM}}$ ) cell lines were obtained from American Type Culture Collection (ATCC, Manassas, VA, USA). The cells were cultivated under $5 \% \mathrm{CO}_{2}$ atmosphere at $37{ }^{\circ} \mathrm{C}$ in a $\mathrm{CO}_{2}$ incubator (Memmert, Schwabach, Germany). A549 cells were grown as an adherent monolayer in F-12K medium (Kaighn's modification of Ham's F-12 medium; Gibco, Paisley, UK), while NIH/3T3 cells were cultivated in Dulbecco's Modified Eagle's Medium (Gibco, Paisley, UK), supplemented with $10 \%$ fetal bovine serum (FBS; Gibco, Paisley, UK) and antibiotics (streptomycin, $50 \mu \mathrm{g} \cdot \mathrm{mL}^{-1}$; amphotericin $\mathrm{B}, 1.25 \mu \mathrm{g} \cdot \mathrm{mL}^{-1}$; gentamicin, $50 \mu \mathrm{g} \cdot \mathrm{mL}^{-1}$; penicillin, $\left.50 \mathrm{U} \cdot \mathrm{mL}^{-1}\right)$ (Gibco, Paisley, UK).

\section{Cytotoxicity assessment}

Cytotoxicity of the studied compounds was assessed based on Alamar Blue and CFE assays.

\section{Alamar Blue assay}

This assay was carried out according to the manufacturer's instruction (Alamar Blue ${ }^{\text {TM }}$ Cell Viability Reagent; Thermo Fisher Scientific, Life Technologies Corporation, Eugene, OR, USA). A549 and NIH/3T3 cells were trypsinized (0.25\% trypsin/EDTA solution; Gibco, Paisley, UK) and plated in 96-well plates (Falcon; Corning, Durham, NC, USA) at a density of $10^{4}$ cells per well. After $24 \mathrm{~h}$ of cell adhesion, the A549 cells were exposed to 
increasing concentrations $\left(0.1,1,5,10,25,50\right.$, and $\left.100 \mu \mathrm{g} \cdot \mathrm{mL}^{-1}\right)$ of QD-MUA, QD-Cys, QD-LA, QD-MUA-FA, QD-Cys-FA, QD-LA-FA, QD-MUA-FA-DOX, QD-CysFA-DOX, QD-LA-FA-DOX, and free DOX, and were further incubated for $24 \mathrm{~h}$, while the control cells were incubated with media. After incubation, the control medium and the investigated compounds were removed. The cells were rinsed twice with PBS, and $100 \mu \mathrm{L}$ of Alamar Blue solution (10\% [v/v] solution of Alamar Blue dye in fresh medium) was transferred to each well. Following $3 \mathrm{~h}$ of incubation $\left(37^{\circ} \mathrm{C}, 5 \% \mathrm{CO}_{2}, 90 \%\right.$ humidity), the Alamar Blue fluorescence was quantified using an Epoch microplate reader (BioTek) at an excitation and emission wavelength of 560 and $590 \mathrm{~nm}$, respectively. The viability of cells was expressed as fluorescence counts in the presence of test compound, which was recalculated as a percentage of the control cells (more details about the NIH/3T3 studies are provided in Additional file 1).

\section{Colony forming efficiency assay}

On the first day, the A549 cells (400/dish) were seeded in $3 \mathrm{~mL}$ of fresh complete medium in 60 -mm Petri dishes. After $24 \mathrm{~h}$ of incubation $\left(37^{\circ} \mathrm{C}, 5 \% \mathrm{CO}_{2}, 90 \%\right.$ humidity), the cells were treated with the most promising QD nanoconjugates, i.e., those that revealed significant cytotoxicity in the Alamar Blue assay, and with free DOX. The concentration values of the QD nanoconjugates was selected based on the Alamar Blue data by applying values close to their $I C_{50}$ concentration (QD-MUA-FA-DOX: 1 and $5 \mu \mathrm{g} \cdot \mathrm{mL}^{-1}$, QDCys-FA-DOX: 10 and $25 \mu \mathrm{g} \cdot \mathrm{mL}^{-1}$, QD-LA-FA-DOX: 5 and $10 \mu \mathrm{g} \cdot \mathrm{mL}^{-1}$, and DOX: 0.1 and $\left.1 \mu \mathrm{g} \cdot \mathrm{mL}^{-1}\right)$. Three replicates per each concentration were performed. Positive control (sodium chromate, $\mathrm{Na}_{2} \mathrm{CrO}_{4}, 100 \mu \mathrm{M}$ ), negative control (medium), and solvent control (PBS) were used in parallel studies. The cells were treated for $72 \mathrm{~h}$, and then, the incubated medium with added nanoconjugates or DOX was removed and completely replaced with fresh culture medium. After the next $72 \mathrm{~h}$, the cells were fixed and stained with a fixing solution of $10 \%(\mathrm{v} / \mathrm{v})$ formaldehyde in PBS and a staining solution of $10 \%$ (v/v) Giemsa in ultrapure water, respectively. The Petri dishes were air-dried before colony counting. The colonies were counted using a stereoscopic microscope (Opti-Tech Scientific).

\section{In vitro scratch assay}

The scratch assay was carried out based on the protocol published by Liang et al. (2007). Briefly, A549 cells $\left(1.5 \times 10^{5}\right.$ cells/well) were seeded in 24 -well plates to grow in a monolayer for $24 \mathrm{~h}$. Then, a "scratch" was created with a sterile $20-200 \mu \mathrm{L}$ pipette tip in each well. The detached cells were removed by washing twice with PBS. Afterward, $250 \mu \mathrm{L}$ of both fresh medium without FBS and the most promising QD nanoconjugates at the final $I C_{50}$ concentration were added and incubated for $72 \mathrm{~h}$. Fresh medium without FBS was used as control, while the positive control was medium with 10\% FBS. Three replicates per concentration were performed. The scratches were observed under a phasecontrast microscope and photographed at the reference point. The scratch closure was monitored at $0,24,48$, and $72 \mathrm{~h}$ of the experiment using a microscope (Delta Optical NIB-100) at a magnification of $\times 4$. The scratch images were analyzed using ImageJ, and 
the scratch area was calculated. The migration of cells toward the scratch was expressed as a percentage of scratch closure:

$$
\% \text { of wound closure }=\frac{A_{\mathrm{t}=0 \mathrm{~h}}-A_{\mathrm{t}=\Delta \mathrm{h}}}{A_{\mathrm{t}=0 \mathrm{~h}}} \cdot 100 \%,
$$

where $A_{\mathrm{t}=0 \mathrm{~h}}$ is the area of wound measured immediately after scratching and $A_{\mathrm{t}=\Delta \mathrm{h}}$ is the area of wound measured 24, 48, or $72 \mathrm{~h}$ postscratching (Yue et al. 2010).

\section{Comet assay}

For the comet assay (single-cell gel electrophoresis), A549 cells $\left(2.5 \times 10^{5}\right.$ cells/well) were seeded in 24-well plates to grow in a monolayer. After $24 \mathrm{~h}$ of cell adhesion, the cells were exposed to the final $I C_{50}$ concentration of the most promising QD nanoconjugates and to free DOX, and were further incubated for $24 \mathrm{~h}$. The control cells were incubated with media and PBS. The positive control consisted of control cells that were X-irradiated (2 Gy) in an ice water bath, using a Smart200 (Yxlon) defectoscope operating at $200 \mathrm{kV}$ and $4.5 \mathrm{~mA}$, with 3-mm Al filtration, at a dose rate of $1.14 \mathrm{~Gy} / \mathrm{min}$. After incubation, the A549 cells were trypsinized and an aliquot of cells was mixed with an equal volume of $2 \%$ low-melting-point agarose (Type VII). The cells were placed on a microscope slide precoated with $0.5 \%$ regular agarose (Type I-A). The slides were immediately placed in a lysis solution and then on a horizontal gel electrophoresis unit filled with fresh electrophoresis buffer $\left(1 \mathrm{mM} \mathrm{Na}{ }_{2}\right.$ EDTA and $300 \mathrm{mM} \mathrm{NaOH}, \mathrm{pH}>13$ for $40 \mathrm{~min}$ for DNA unwinding). Next, electrophoresis was performed $\left(1.2 \mathrm{~V} \cdot \mathrm{cm}^{-1}, 30 \mathrm{~min}, 10^{\circ} \mathrm{C}\right)$,

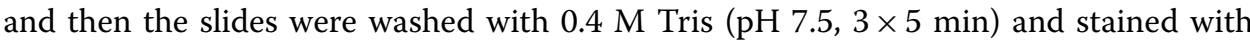
DAPI $\left(50 \mu \mathrm{L}, 1 \mu \mathrm{g} \cdot \mathrm{mL}^{-1}\right)$. Images of 100 randomly selected comets per slide were captured at a magnification of $\times 200$ using a fluorescence microscope (Labophot-2, Nikon, Japan) which was equipped with a Pulnix TM765 CCD camera (JAI, Japan). Image analysis of the data was performed in Comet v.3.0 software (Kinetic Imaging Ltd., UK).

\section{Statistical analysis}

Data are presented as the mean value $\pm \mathrm{SD}$. The study was conducted in at least three independent runs. Graphs were prepared in GraphPad Prism 9 (GraphPad Software, Inc, La Jolla, CA, USA). Statistical analysis was performed with Statistica and GraphPad Prism software using an unpaired $t$-test or Mann-Whitney $U$ test. $P<0.05$ was considered statistically significant.

\section{Results and discussion}

\section{Qualitative features of the FTIR spectra of the QD-FA nanocarriers and QD-FA-DOX nanoconjugates}

The exact details about the functional groups involved in conjugation between the QD nanocrystals and FA and DOX can be obtained by comparison of the FTIR spectra of pure QDs, FA, and DOX with that of the QD-FA nanocarriers and QD-FADOX nanoconjugates. The FTIR spectra of pure components, nanocarriers, and nanoconjugates are given in Fig. 2. For all the studied QD nanocrystals (Fig. 2a), the characteristic stretching vibrations of $\mathrm{C}=\mathrm{O}$ at $c a .1560 \mathrm{~cm}^{-1}$ and $\mathrm{O}-\mathrm{H}$ in-plane band for carboxylate groups at $c a .1410 \mathrm{~cm}^{-1}$ were visible. As shown in Fig. $2 \mathrm{~b}$, for pure FA, 

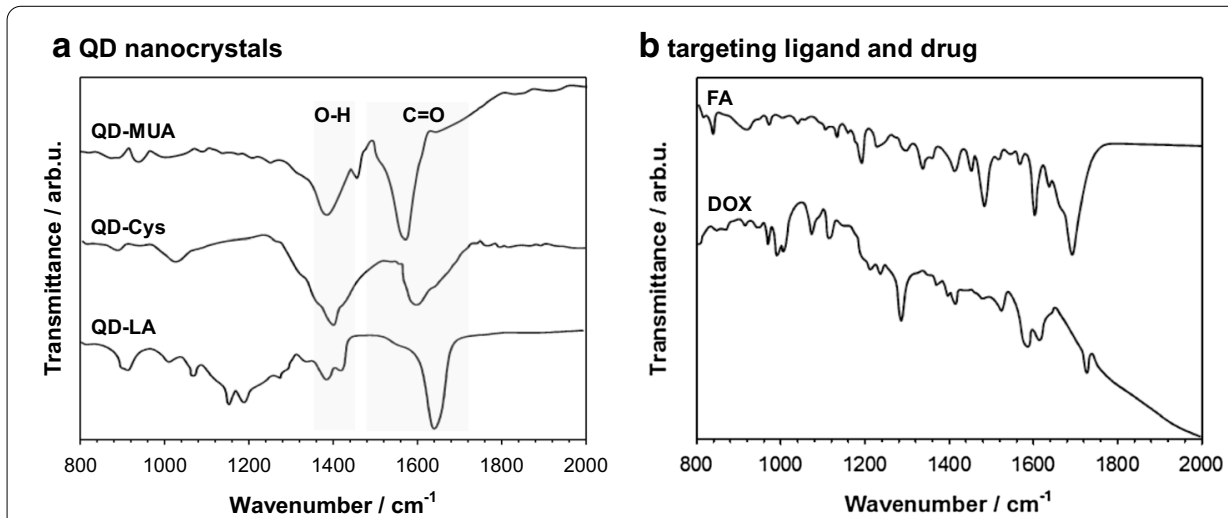

C QD-FA nanocarriers

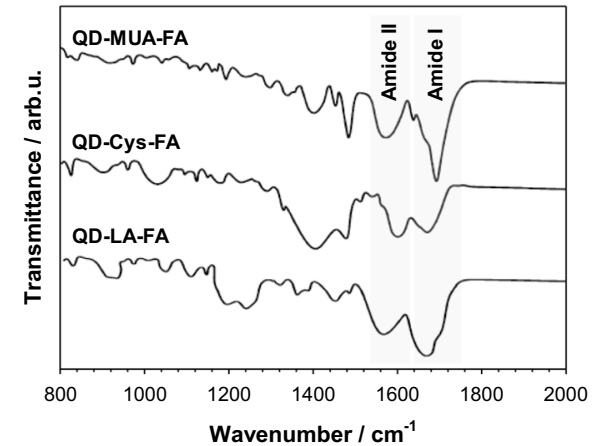

d QD-FA-DOX nanoconjugates

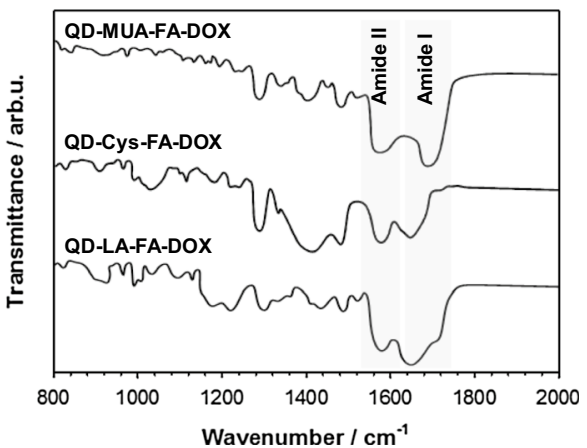

Fig. 2 Representative Fourier transformation infrared spectra of the QD nanocrystals (a), targeting ligand and drug (b), QD-FA nanocarriers (c), and QD-FA-DOX nanoconjugates (d). The spectra were standardized by a background spectrum determined on the bare KBr substrate. QD Ag-In-Zn-S nanocrystals modified with: 11-mercaptoundecanoic acid (MUA), Cys L-cysteine, LA lipoic acid, FA folic acid, DOX doxorubicin

the stretching vibration of $\mathrm{C}=\mathrm{O}$ was noted at $1696 \mathrm{~cm}^{-1}$, while the band at $1607 \mathrm{~cm}^{-1}$ was related to the bending mode of the $\mathrm{NH}$ - vibration. The bands between 1513 and $1485 \mathrm{~cm}^{-1}$ were attributed to phenyl and pterin rings (Zhang et al. 2008). In turn, the FTIR spectrum of DOX indicated characteristic bands at $1730 \mathrm{~cm}^{-1}(\mathrm{C}=\mathrm{O}$ stretch, ketone), $1630 \mathrm{~cm}^{-1}$ ( $\mathrm{C}=\mathrm{O}$ stretch), $1282.7 \mathrm{~cm}^{-1}\left(\mathrm{C}-\mathrm{O}-\mathrm{C}\right.$, stretch), $1114 \mathrm{~cm}^{-1}(\mathrm{C}-\mathrm{O}$ stretch, tertiary alcohol), $1070 \mathrm{~cm}^{-1}$ (C-O stretch, secondary alcohol), and $988 \mathrm{~cm}^{-1}$ (C-O stretch, primary alcohol) (Kanwal et al. 2019; Stanishevsky et al. 2011). The FTIR spectrum of the QD-FA nanocarriers presented in Fig. 2c shows the characteristic bands for QD nanocrystals and FA. The effect of conjugation of QDs with FA via amide bond was characterized by amide I and amide II bands. The amide I band corresponded mainly to the $\mathrm{C}=\mathrm{O}$ stretching vibration of the amide groups and occurred in the region $1600-1700 \mathrm{~cm}^{-1}$. The amide II band $\left(1480-1575 \mathrm{~cm}^{-1}\right)$ was attributed to $\mathrm{N}-\mathrm{H}$ bending $(40-60 \%)$ and $\mathrm{C}-\mathrm{N}$ stretching $(18-40 \%)$ vibrations (Coates et al. 2000, Thomas et al. 1977). After covalent (via amide bond, Fig. 2d) conjugation of DOX to QD-FA nanocarriers, several important features characteristic of this drug appeared on the FTIR spectrum of the QD-FA-DOX nanoconjugates. Additionally, a small shift in the amide I and amide II positions was observed with respect to pure 
components. Moreover, the presence of the bands that are characteristic of the drug, at $c a .1300 \mathrm{~cm}^{-1}$, confirmed the successful attachment of DOX.

\section{QD fluorescence quenching studies as a proof of QD and FA conjugation}

The interactions of FA with each type of QD nanocrystals were examined using fluorescence titrations. The effect of FA concentration on the emission spectra of appropriate QDs is illustrated in Fig. 3. The examined QD-MUA, QD-Cys, and QD-LA nanocrystals were characterized by an emission maximum at $c a .573,545$, and 551 , respectively. In all the cases, the addition of FA led to a gradual decrease in fluorescence with

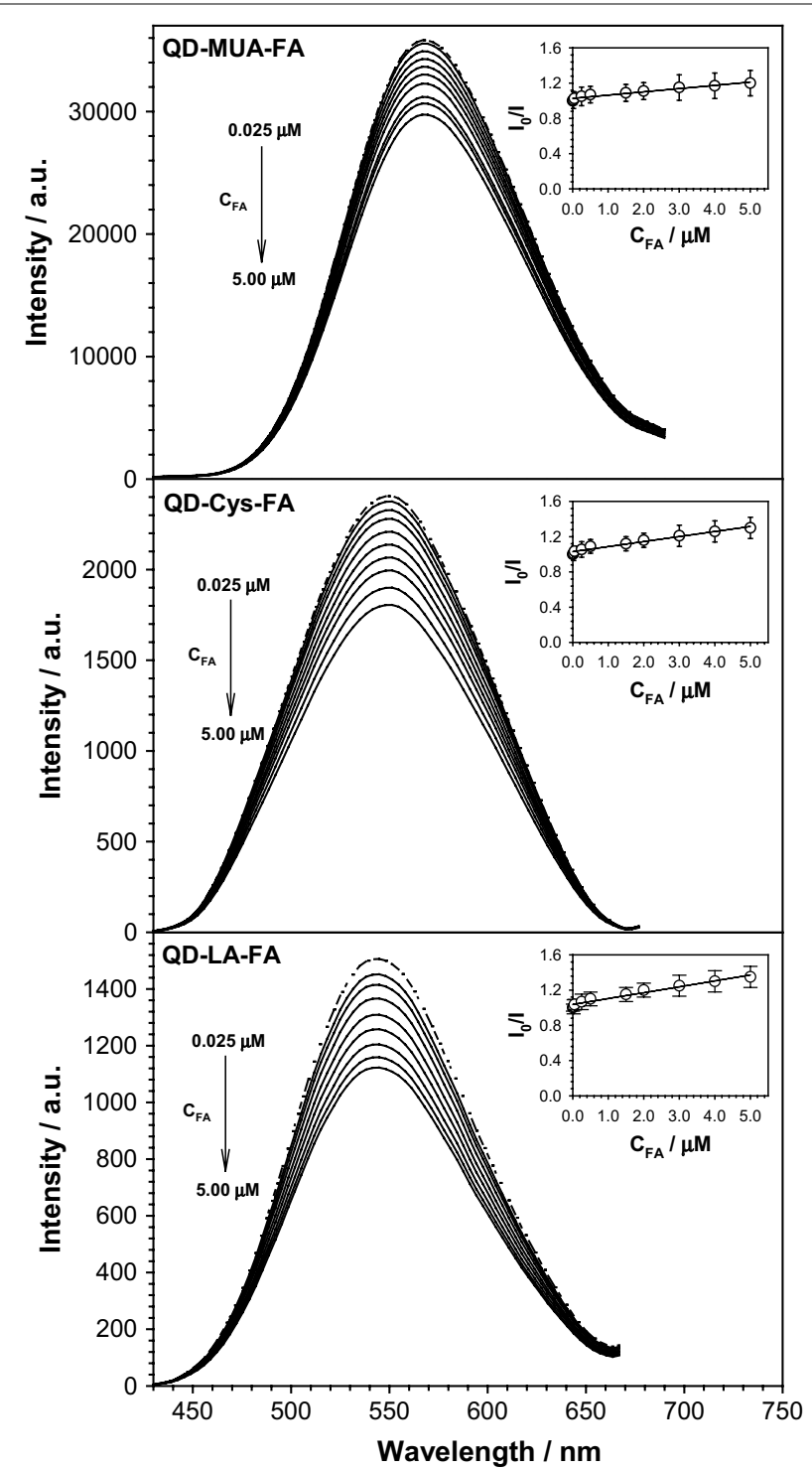

Fig. 3 Fluorescence quenching of QDs by FA in $0.02 \mathrm{M}$ phosphate-buffered saline of $\mathrm{pH} 7.4(n=5)$. Insets: Stern-Volmer plots of QD quenching fluorescence as a function of FA concentrations. Experimental conditions: $C_{\mathrm{QD}}=1 \mathrm{mg} \cdot \mathrm{mL}^{-1} ; C_{F A}=0.025,0.05,0.25,0.5,1.5,2,3,4$, and $5 \mu \mathrm{M} ; \lambda_{\text {ex }}=350 \mathrm{~nm} ;$ PMT voltage: $700 \mathrm{~V}$; PMT integration time: $20 \mathrm{~ms}$; scan speed: $600 \mathrm{~nm} \cdot \mathrm{min}^{-1}$. QD Ag-In-Zn-S nanocrystals modified with: 11-mercaptoundecanoic acid (MUA), Cys L-cysteine, LA lipoic acid, FA folic acid 
an increase in concentration in the solutions. In particular, for the highest FA content $(5 \mu \mathrm{M})$, the fluorescence intensities were quenched to $c a .80$ and $75 \%$ of the original value of QD-MUA and QD-Cys or QD-LA, respectively. The QD-FA interactions can be quantitatively described by the quenching constant $\left(K_{\mathrm{SV}}\right)$ of the QD-FA nanocarriers using the Stern-Volmer equation (Li et al. 2005, Olsztynska et al. 2011, Pyle et al. 1989):

$$
\frac{I_{0}}{I}=1+K_{\mathrm{SV}} \cdot C_{\mathrm{FA}},
$$

where $C_{\mathrm{FA}}$ is the molar concentration of FA and $I_{0}$ and $I$ are the fluorescence intensities of QD in the absence and presence of FA, respectively. $K_{\mathrm{SV}}$ values were calculated from the slopes of the each plot of $I_{0} / I=\mathrm{f}\left(C_{\mathrm{FA}}\right)$ and were equal to $(3.7 \pm 0.3) \cdot 10^{4}$, $(5.7 \pm 0.4) \cdot 10^{4}$, and $(6.7 \pm 0.5) \cdot 10^{4} \mathrm{M}^{-1}$ for QD-MUA-FA, QD-Cys-FA, and QD-LAFA, respectively. The Stern-Volmer plots were linear (insets in Fig. 3), so only one type of quenching process occurred, either static or dynamic (Lakowicz et al. 2010; Zhong et al. 2001). The simplest way to distinguish the static from dynamic quenching is to monitor the changes in $K_{\mathrm{SV}}$ as a function of temperature (Lakowicz et al. 2010). The increase of $K_{\mathrm{SV}}$ value with temperature indicates dynamic quenching, while the opposite behavior is typical for static quenching. For all the QD-FA nanocarriers, a decrease in $K_{\mathrm{SV}}$ value was observed with an increasing temperature. Such behavior suggested that static quenching occurred and, subsequently, the quenching constant could be considered as association constant.

\section{Size and physical stability of the QD-FA nanocarriers and QD-FA-DOX nanoconjugates}

The size of the QD nanocrystals, QD-FA nanocarriers, and QD-FA-DOX nanoconjugates was considered as one of the qualitative parameters proving the successful conjugation process. Based on the DLS studies, the diameter of the QD nanocrystals dispersed in PBS buffer was determined to differ in the range of 11-19 $\mathrm{nm}$ depending on the type of surface ligand (Fig. 4).

It should be stressed that the hydrodynamic diameter of QD nanocrystals was significantly higher than those determined from the TEM images (Table 1). The highest diameter of QD nanoconjugates was observed for those with LA as a surface ligand. This can be explained by the different number of zinc atoms, and in consequence, the differences in the number of ligands stabilizing them. Probably, two coordination spheres of ligands exist. The first sphere contains ligands directly bound to the surface, while the second includes free ligands that are in balance with the first-sphere ligands. During bioconjugation, the size of the QD nanocrystals increased along with another modification of their surface by FA and DOX. The tendency of nanocarriers to accumulate in the target tissue depends on their physicochemical properties including particle size and distribution. The safe, stable, and efficient nanocarriers require the preparation of homogenous (monodisperse) populations, characterized by a certain particle size. The polydispersity index (PDI), defining the degree of nonuniformity of the size distribution of particles, decreases with the subsequent modifications of QD nanocrystals (Fig. 4). A reduction in PDI testifies that the size distribution of nanoparticles is narrowing. A PDI value of greater than 0.2 is mainly seen in the case of highly monodisperse nanocrystals. 


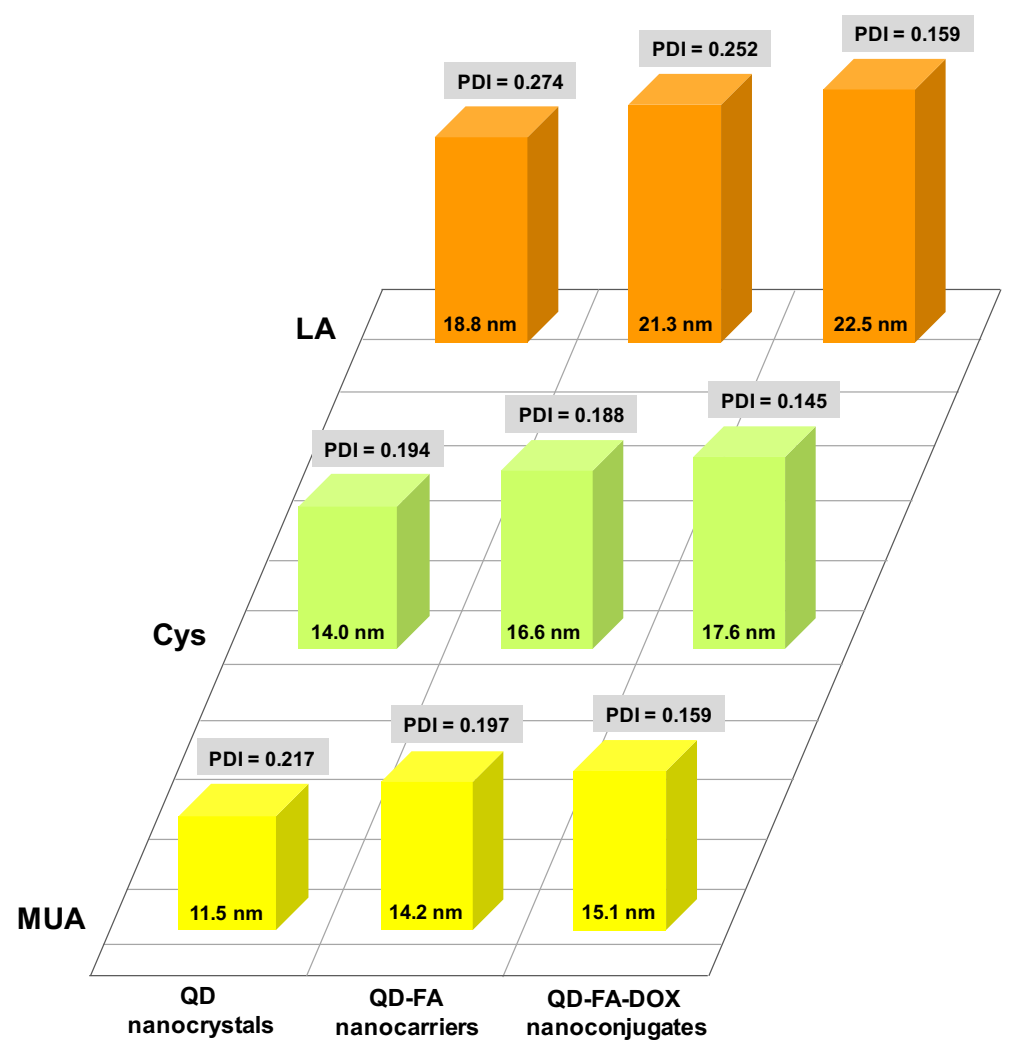

Fig. 4 Mean size and polydispersity index of the QD nanocrystals, QD-FA nanocarriers, and QD-FA-DOX nanoconjugates dispersed in phosphate-buffered saline based on dynamic light scattering studies $(n=5)$. QD Ag-In-Zn-S nanocrystals modified with: 11-mercaptoundecanoic acid (MUA), Cys L-cysteine, LA lipoic acid, FA folic acid, DOX doxorubicin

Table 2 ZP values of the QD nanocrystals, QD-FA nanocarriers, and QD-FA-DOX nanoconjugates obtained in PBS buffer $(n=5)$

\begin{tabular}{lccc}
\hline & MUA & Cys & LA \\
\hline QD & $-23.3 \pm 2.4$ & $-24.3 \pm 3.5$ & $-10.9 \pm 1.2$ \\
QD-FA & $-34.1 \pm 2.6$ & $-27.8 \pm 2.7$ & $-13.2 \pm 2.2$ \\
QD-FA-DOX & $-15.5 \pm 3.5$ & $-17.2 \pm 1.9$ & $-6.2 \pm 1.1$ \\
\hline
\end{tabular}

QD Ag-In-Zn-S nanocrystals modified with: 11-mercaptoundecanoic acid), Cys L-cysteine, LA lipoic acid, FA folic acid, DOX doxorubicin

ZP was considered as one of the decisive factors of the stability of QD nanocrystals, QD-FA nanocarriers, and QD-FA-DOX nanoconjugates. The obtained ZP values are shown in Table 2. ZP plays an essential role in the stability of the QD-FA-DOX nanoconjugates. The higher the ZP value (positive or negative), the more stable is the dispersion. In general, nanoparticles with a $\mathrm{ZP}$ value of greater than $+30 \mathrm{mV}$ or less than $-30 \mathrm{mV}$ have a high degree of stability. Dispersions with a ZP value of less than $+25 \mathrm{mV}$ or greater than $-25 \mathrm{mV}$ will eventually agglomerate due to interparticle interactions, including van der Waals and hydrophobic interactions, as well as hydrogen bonding. In this study, the smallest ZP values were observed for the QDFA-DOX nanoconjugates among the tested types of QDs. This fact suggests that such 
Table 3 Mass of FA and DOX anchored to $1 \mathrm{~g}$ of each type of QD nanocrystals

\begin{tabular}{|c|c|c|c|c|}
\hline & \multicolumn{2}{|c|}{$\begin{array}{l}m_{\mathrm{FA}} / 1 \mathrm{~g} Q D \\
{[\mathrm{mg}]}\end{array}$} & \multicolumn{2}{|c|}{$\begin{array}{l}m_{\mathrm{Dox}} / 1 \mathrm{~g} \mathrm{QD} \\
{[\mathrm{mg}]}\end{array}$} \\
\hline & Exp & Theor & Exp & Theor \\
\hline QD-MUA & 11 & 28 & 46 & 56 \\
\hline QD-Cys & 13 & 50 & 54 & 102 \\
\hline QD-LA & 9 & 21 & 39 & 42 \\
\hline
\end{tabular}

QD Ag-In-Zn-S nanocrystals modified with: 11-mercaptoundecanoic acid), Cys L-cysteine, LA lipoic acid, FA folic acid, DOX doxorubicin

Table 4 Diameter $(\varphi)$, radius $(r)$, density $(\rho)$, volume of single QD molecules $\left(V_{\mathrm{QD}}\right)$, and the number of QD molecules $\left(N_{\mathrm{QD}}\right)$

\begin{tabular}{llllll}
\hline & $\begin{array}{l}\boldsymbol{\varphi} \\
{[\mathbf{n m}]}\end{array}$ & $\begin{array}{l}\boldsymbol{r} \\
{[\mathrm{nm}]}\end{array}$ & $\begin{array}{l}\boldsymbol{\rho} \\
{\left[\mathbf{g} \cdot \mathbf{c m}^{-3}\right]}\end{array}$ & $\begin{array}{l}\boldsymbol{V}_{\mathrm{QD}} \\
{\left[\mathrm{cm}^{-3}\right]}\end{array}$ & $\begin{array}{l}\boldsymbol{N}_{\mathrm{QD}} \\
\text { in 1 }\end{array}$ \\
\hline QD-MUA & 11.5 & 5.7 & 4.51 & $7.75 \cdot 10^{-19}$ & $2.86 \cdot 10^{17}$ \\
QD-Cys & 14.0 & 7.0 & 2.63 & $6.23 \cdot 10^{-19}$ & $6.10 \cdot 10^{17}$ \\
QD-LA & 18.8 & 9.4 & 3.60 & $3.48 \cdot 10^{-18}$ & $7.99 \cdot 10^{16}$ \\
\hline
\end{tabular}

$\varphi$ QD nanoparticle diameter, $r$ QD nanoparticle radius, $\rho: Q D$ density determined on the basis of the density of its components, $V_{\mathrm{QD}}$ volume of a single QD molecule $\left(\mathrm{V}_{\mathrm{QD}}=\frac{4}{3} \pi r^{3}\right), N_{\mathrm{QD}}$ number of QD molecules in $1 \mathrm{~g}, \mathrm{QD} \mathrm{Ag}-\mathrm{In}-\mathrm{Zn}-\mathrm{S}$ nanocrystals modified with: 11-mercaptoundecanoic acid (MUA), Cys L-cysteine, LA lipoic acid

behavior might be favorable for the release of DOX from nanoconjugates in the cell culture medium.

\section{Quantitative analysis of the QD-FA nanocarriers and QD-FA-DOX nanoconjugates}

The amount of FA and DOX covalently anchored to the surface of QD nanocrystals was determined from the UV-Vis analysis (Table 3).

It should be noted that these values corresponded to $c a$. $30-40 \%$ of the maximal value for FA, which most likely represents the lower limit of surface coverage. This is probably due to steric reasons, as some FA molecules lie on the ligand layer at the QD surface and efficiently block the conjugations sites. The mass of DOX covalently attached to the QD-FA nanocarriers corresponded to $c a$. $50-80 \%$ of the maximal value for FA, which most likely represents the higher limit of surface coverage. It is possible that DOX molecules were anchored to the QD-FA nanocarriers via amide bonds with FA molecules, as well as directly with the ligand at the QD surface. While calculating the maximal mass of FA and DOX, it was assumed that DOX molecules are two-dimensionally closely packed on the surface of QD, and the maximal number of DOX molecule per QD molecule is:

$$
\frac{\mathrm{S}_{\mathrm{D}}}{\mathrm{S}_{D O X}}=\frac{4 \pi r^{2}}{\pi r^{2}}=205,175 \text { and } 550 \text { for QD-MUA, QD-Cys, and QD-LA, respectively; }
$$
and $\frac{\mathrm{S}_{\mathrm{QD}}}{\mathrm{S}_{F A}}=\frac{4 \pi r^{2}}{\pi r^{2}}=132,113$ and 355 for QD-MUA, QD-Cys, and QD-LA, respectively.

Taking into account the composition of the studied QD nanocrystals-QDMUA $\quad\left(\mathrm{Ag}_{1.00} \mathrm{In}_{1.20} \mathrm{Zn}_{5.60} \mathrm{~S}_{9.40}\right)$, QD-Cys $\left(\mathrm{Ag}_{1.00} \mathrm{In}_{6.80} \mathrm{Zn}_{14.30} \mathrm{~S}_{154.20}\right)$, and QD-LA $\left(\mathrm{Ag}_{1.00} \mathrm{In}_{1.00} \mathrm{Zn}_{8.80} \mathrm{~S}_{25.10}\right)$-the densities of QDs were determined from the density of their components and are presented in Table 4. From the volume of a single QD molecule, the number of QDs in $1 \mathrm{~g}$, the mass of FA or DOX corresponding to the maximal number of QD, and the maximal (theoretical) mass of FA and DOX covalently attached to $1 \mathrm{~g}$ of QD nanocrystals were estimated. 
DOX is an anticancer drug commonly used to treat leukemia, organ tumors, Hodgkin's disease, and bladder, stomach, lung, and thyroid cancer (Wakharde et al. 2018). Due to cardiotoxicity and myelosuppression, DOX has a very narrow therapeutic index (Jung and Rezska 2001). Moreover, drug resistance is also an important issue associated with the use of DOX. To eliminate the undesirable side effects, DOX is commonly equipped with an appropriate nanocarrier. Targeted drug delivery (TDD) nanosystems increase the therapeutic activity of the drug by improving its solubility and stability and enhancing the amount of drug delivered to the target tissue (Maghsoudnia et al. 2020). Many types of DOX carriers are known ranging from metal or carbon nanoparticles, to lipid carriers such as liposomes and QDs (nanocrystals) (Li et al. 2017, Silverman et al. 2013, Verma et al. 2015). The latter have enormous potential in both therapy and diagnostics. However, the main drawbacks of QDs, namely core toxicity and low hydrophilicity, impede their widespread implementation. To improve the hydrophilicity and biocompatibility of QD nanocrystals, many different strategies have been applied including the attachment of hydrophilic moieties to their surface (Derfus et al. 2003; Kaaki et al. 2012; Michalet et al. 2005), and their encapsulation within amphiphilic copolymer micelles (Gao et al. 2005), phospholipid micelles (Dubertret et al. 2002), or silica polymers (Gerion eta al. 2001). Modification of the surface of QDs limits their tendency to aggregate, significantly reduces their cytotoxicity, and also allows overcoming drug resistance mechanisms. However, labeling of QDs with target-specific ligands, such as FA, aptamers, peptides, and antibodies, unfortunately increases their size significantly (Jin et al. 2020). The size of a nanocarrier and its drug conjugate has an influence on the cellular uptake and tumor permeability of nanoparticles (Albanese et al. 2012; Chauhan et al. 2012; Hobbs et al. 1998; Peretz et al. 2012). In the case of lung cancers, drug delivery systems with a diameter less than $50 \mathrm{~nm}$ are characterized by optimal efficiency of delivery into the pulmonary system (Hussain et al. 2001; Xu et al. 2019). Taking into account the size of QD-FA-DOX as well as the content of DOX in the nanoconjugate, our proposition seems to be very attractive (Table 5).

\section{Cytotoxicity assessment}

One of the most important objectives of our study was to assess the cytostatic activity of the as-obtained QD nanoplatforms loaded with and without DOX. Therefore,

Table 5 Comparison of the QD-FA-DOX nanoconjugates

\begin{tabular}{lllll}
\hline Nanoconjugate & $\begin{array}{l}\text { Size } \\
{[\mathbf{n m}]}\end{array}$ & PDI & $\begin{array}{l}\text { DOX content } \\
{[\%]}\end{array}$ & Ref \\
\hline Ag 2 S NIRQD-PEG-FA-DOX & 27 & 0.291 & 3.67 & Duman et al. 2017 \\
ZnO:Mn ${ }^{+2}$ QD-CHI-FA-DOX & 29.4 & 0.228 & - & Bajwa et al. 2016 \\
MSNs-CDs@FA-DOX & 75 & - & 2.5 & Zhao et al. 2019 \\
QD-MUA-FA-DOX & 15.1 & 0.159 & 4.6 & This work \\
QD-Cys-FA-DOX & 17.6 & 0.145 & 5.4 & \\
QD-LA-FA-DOX & 22.5 & 0.159 & 3.9 &
\end{tabular}

$\mathrm{Ag}_{2} \mathrm{~S}$ NIRQDs $\mathrm{Ag}_{2} \mathrm{~S}$ near-infrared quantum dots, CDs carbon dots, $\mathrm{CHI}$ chitosan, Cys L-cysteine, DOX doxorubicin, FA folic acid, LA lipoic acid, MSNs amino-modified mesoporous silica nanoparticles, MUA 11-mercaptoundecanoic acid, PDI polydispersity index, PEG amine-polyethylene glycol-valeric acid 
relevant tests were conducted on A549 cells, with the commonly used anticancer drug DOX alone serving as a reference compound.

\section{Alamar Blue assay}

In the present study, A549 cells were in vitro-treated with QD-MUA, QD-Cys, and QD-LA nanocrystals; QD-MUA-FA, QD-Cys-FA, and QD-LA-FA nanocarriers; and QD-MUA-FA-DOX, QD-Cys-FA-DOX, and QD-LA-FA-DOX nanoconjugates; as well as free DOX for $24 \mathrm{~h}$. NIH/3T3 cells were used as FAR-negative controls (Additional file 1). The results of the cell viability measurements showed the lowest reduction of Alamar Blue for A549 cells treated with the QD-Cys-FA-DOX nanoconjugates (Fig. 5d). QD-MUA-FA-DOX nanoconjugate was found to be the most cytotoxic among the studied nanoconjugates (Fig. $5 \mathrm{~d}$ ) since its $I C_{50}$ value was $1.7 \mu \mathrm{g} \cdot \mathrm{mL}^{-1}$ (95\% CI: $0.9-2.7 \mu \mathrm{g} \cdot \mathrm{mL}^{-1}$ ), while the $I C_{50}$ values determined for QDCys-FA-DOX and QD-LA-FA-DOX nanoconjugates were $10.5 \mu \mathrm{g} \cdot \mathrm{mL}^{-1}(95 \% \mathrm{CI}$ : $\left.7.7-13.8 \mu \mathrm{g} \cdot \mathrm{mL}^{-1}\right)$ and $5.5 \mu \mathrm{g} \cdot \mathrm{mL}^{-1}\left(95 \% \mathrm{CI}: 4.0-7.3 \mu \mathrm{g} \cdot \mathrm{mL}^{-1}\right.$ ), respectively. The successful application of $\mathrm{Ag}-\mathrm{In}-\mathrm{Zn}-\mathrm{S}$ QDs with MUA as a linker in anticancer therapy has been recently reported by Pilch et al. (2020). The authors used QD-MUA as a carrier of bisacridine derivatives (UAs) for enhancing their cytotoxicity toward
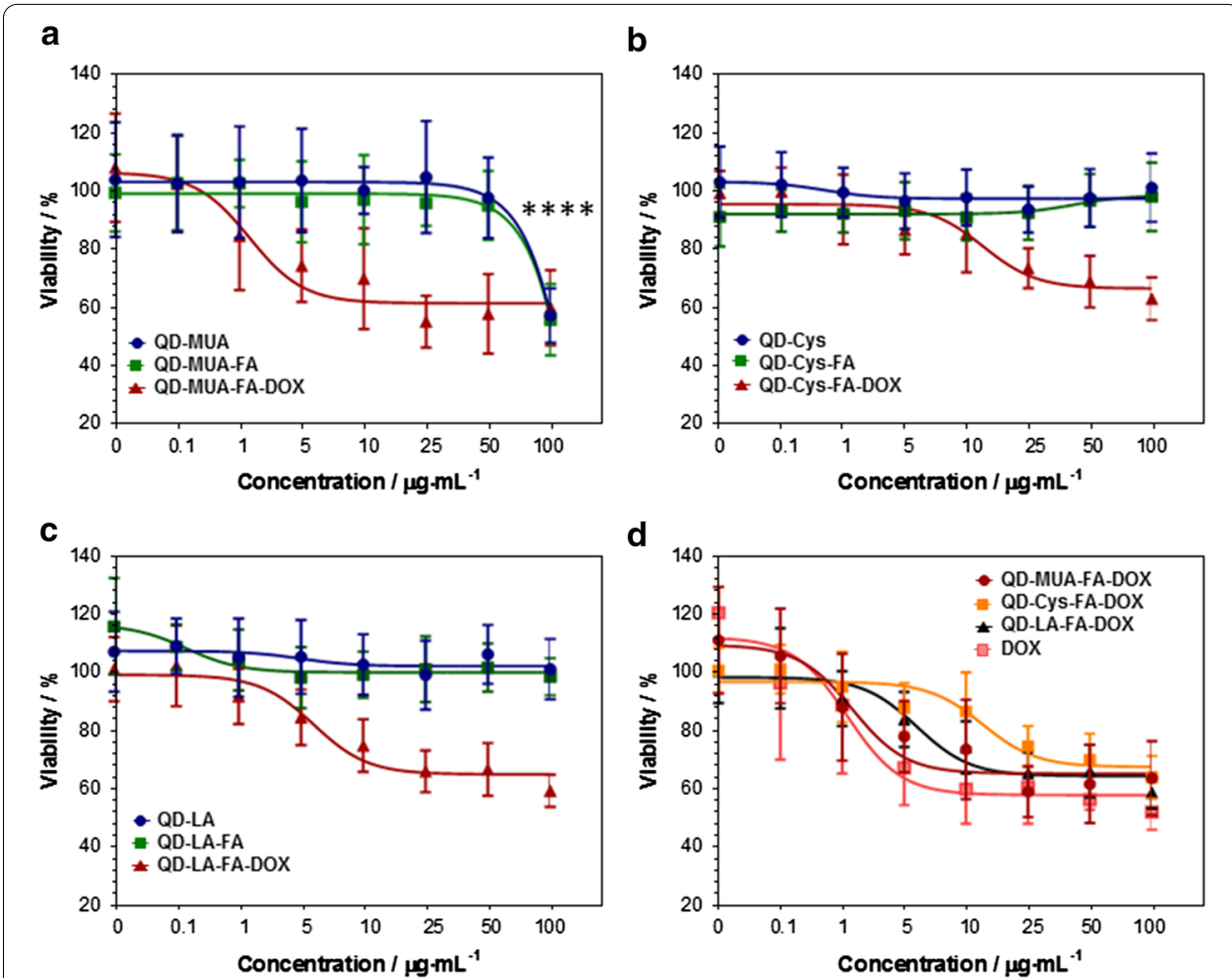

Fig. 5 Viability of human lung carcinoma cells (A549) treated with QDs coated with MUA (a), Cys (b), LA (c), and QDs (d) functionalized with FA and DOX and free DOX. Data were obtained from three independent experiments $(n=6)$. ${ }^{* * *} P<0.0001$ vs. A549 cells treated with $50 \mu \mathrm{g} \cdot \mathrm{mL}^{-1}$ of QD-MUA and QD-MUA-FA (unpaired t-test). QD Ag-In-Zn-S nanocrystals modified with: 11-mercaptoundecanoic acid (MUA), Cys L-cysteine, LA lipoic acid, FA folic acid, DOX doxorubicin 
cancerous cells. As a result, they observed an increase in the therapeutic efficiency of UAs toward lung (H460) and colon (HCT116) cancer cells, while protective effect on normal cells was preserved.

No cytotoxic effect was observed for the studied QD nanocrystals, except QD-MUA, at the highest concentration (Fig. 5a). A significant cytotoxic effect was observed for QD-MUA after treatment at a concentration of $100 \mu \mathrm{g} \cdot \mathrm{mL}^{-1}$, similarly to its derivative (QD-MUA-FA) obtained by the conjugation of FA (Fig. 5a). In both cases, about $40 \%$ loss of cell viability was noted in comparison to the preceding studied concentration $\left(50 \mu \mathrm{g} \cdot \mathrm{mL}^{-1}\right)$. In other recent studies, no cytotoxicity of QD-MUA on H460 and HCT116 cancerous cells and on MRC-5 and CCD 841CoN normal cells was reported (Pilch et al. 2020). Interestingly, the cytotoxicity of MUA in the absence of QDs core was investigated by Hoshino et al. who revealed severe toxic effects at doses greater than $100 \mu \mathrm{g} \cdot \mathrm{mL}^{-1}$ within $12 \mathrm{~h}$ of treatment (Hoshino et al. 2004). It should be noted that FA-functionalized QDs were found to have an ambiguous effect on the cytotoxicity of studied cells. The treatment of A549 cells with the highest applied concentration of QDCys-FA slightly increased their viability (Fig. 5b), whereas treatment with QD-LA-FA did not influence the cells regardless of the tested concentrations (Fig. 5c). It was previously reported that FA plays a great role as a ligand in targeted cancer therapy; however, its excessive supplementation may lead to neocarcinogenesis and promote the progression of some cancers (Araghi et al. 2019, Oliai et al. 2019; Petersen et al. 2012; Pieroth et al. 2018). In this study, A549 cells were also treated with free DOX. The Alamar Blue assay revealed a quite different profile for free DOX and DOX-conjugated QDs as the $I C_{50}$ of DOX was established at $0.8 \mu \mathrm{g} \cdot \mathrm{mL}^{-1}$ and that of QD-MUA-FA-DOX (QD with the highest cytotoxic effect) at $1.7 \mu \mathrm{g} \cdot \mathrm{mL}^{-1}$. It must be emphasized that $1.7 \mu \mathrm{g} \cdot \mathrm{mL}^{-1}$ of QD-MUA-FA-DOX contained $0.08 \mu \mathrm{g} \cdot \mathrm{mL}^{-1}$ of DOX, which is 10 times lesser than the $I C_{50}$ value of free DOX. One has to be noted that QD-based nanocarriers contained a lower amount of DOX as compared to free DOX used in the cytotoxicity assay (Table 3).

In this study, NIH/3T3 cells were used as an FAR-negative cell line and as a reference for the assessment of DOX delivery through the FAR to A549 cells in the experiment (Elkhodiry et al. 2016). It was found that the $I C_{50}$ value of QD-MUA-FA-DOX for A549 cells was c.a. 3.5 times lesser than that for $\mathrm{NIH} / 3 \mathrm{~T} 3$, while the $I C_{50}$ values of free DOX for both lines were at a comparable level $\left(I C_{50 \mathrm{~A} 549}=0.6 \mu \mathrm{g} \cdot \mathrm{mL}^{-1}\right.$ and $I C_{50}$ $\left.\mathrm{NIH} / 3 \mathrm{~T} 3=0.8 \mu \mathrm{g} \cdot \mathrm{mL}^{-1}\right)$. This suggests the successful delivery of DOX to A549 cells by the proposed QD-based TDD system decorated with FA ligands which navigate to FARs on lung cancer cells (Additional file 1).

\section{Colony forming efficiency assay}

CFE assay is used for the assessment of cytotoxicity induced by both chemicals and nanomaterials, based on the ability of a single cell to form a colony (Bendale et al. 2017). The assay provides information on the number of colonies, which is an important parameter of tumor growth and progression. It is also considered to be a promising tool to study label-free nanomaterials (noncolorimetric, nonfluorescent), and therefore limits the possibility of interferences especially associated with optical detection (Ponti et al. 2014). 


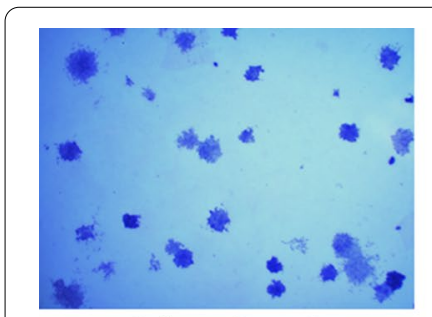

Solvent Control

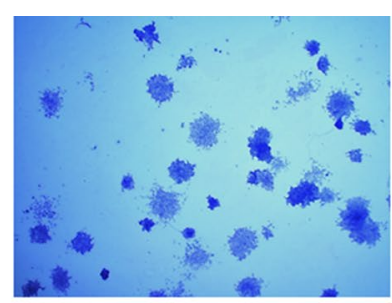

Control

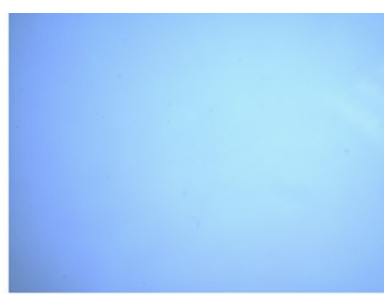

Positive Control

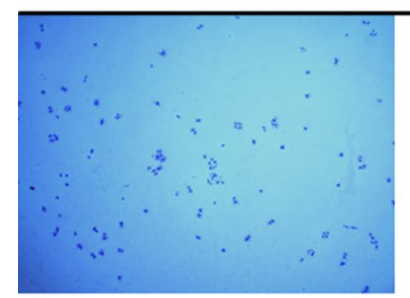

QD-MUA-FA-DOX $1 \mu \mathrm{g} / \mathrm{ml}$

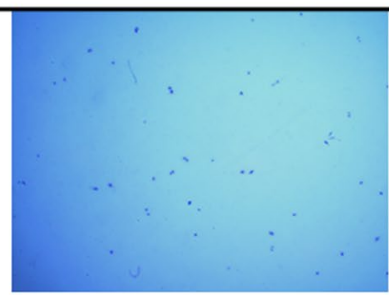

QD-Cys-FA-DOX $10 \mu \mathrm{g} / \mathrm{ml}$

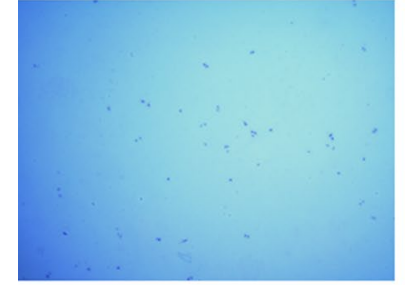

QD-MUA-FA-DOX $5 \mu \mathrm{g} / \mathrm{ml}$

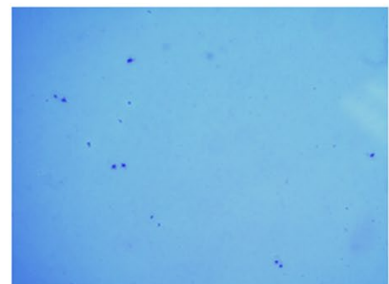

QD-Cys-FA-DOX $25 \mu \mathrm{g} / \mathrm{ml}$

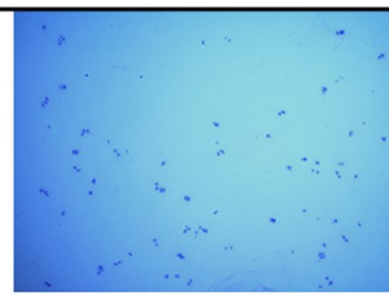

QD-LA-FA-DOX $5 \mu \mathrm{g} / \mathrm{ml}$

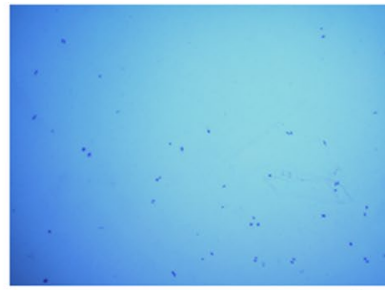

QD-LA-FA-DOX $10 \mu \mathrm{g} / \mathrm{ml}$

Fig. 6 Representative microscopic images of A549 cells from colony forming efficiency assay. Solvent control and control images present the fully developed colonies with $\geq 50$ cells. Images from QD-treated cells present colonies of 2-10 cells or single cells. Images were obtained under a stereoscopic microscope (Opti-Tech Scientific) at a magnification of $\times 2$. QD Ag-In-Zn-S nanocrystals modified with: 11 -mercaptoundecanoic acid (MUA), Cys L-cysteine, LA lipoic acid, FA folic acid, DOX doxorubicin

In this study, the CFE assay was used to confirm the growth inhibition of A549 cells by the most promising QD nanoconjugates at the concentrations exhibiting the significant the cytotoxic effect (i.e., all the QD nanoconjugates with FA and DOX), as established based on the Alamar Blue test. The control and solvent control revealed a plating efficiency of more than $45 \%$ (Fig. 6). As a rule, colonies with more than 50 cells should be counted in the CFE assay (Bendale et al. 2017); however, in our experiment, the selected concentrations of the QD nanoconjugates strongly suppressed the growth of A549 cells, leading to a reduction in the number and size of colonies with more than 50 cells within. As a consequence, no colonies of 50 cells were evidenced (excluding both controls). Nevertheless, many small colonies containing 2-10 cells were observed (Fig. 6); therefore, the comparative analysis was only limited to this group. The colonies containing 11-25 cells and 25-50 cells were also investigated; however, these occurred in a large minority. Taken together, this indicates that all QD nanoconjugates strongly inhibited the growth ability of A549 cells. Interestingly, among the colonies formed, a different shape was observed for the treated cells as compared to the respective controls (Fig. 6).

The CFE assay revealed that treatment with QD nanoconjugates enhanced cell death in a concentration-dependent manner as a reduction in the size and number of 


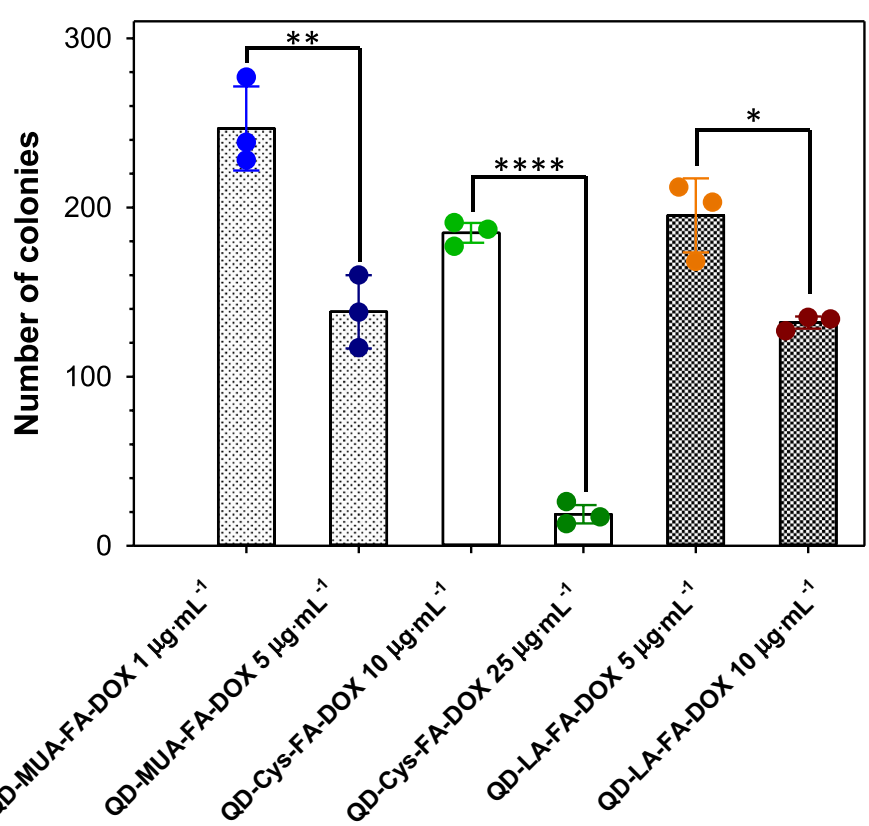

Fig. 7 Number of colonies made of 2-10 human lung carcinoma cells (A549) treated with QD-MUA-FADOX, QD-Cys-FA-DOX, and QD-LA-FA-DOX. Data were obtained from three independent experiments. ${ }^{*} P<0.05,{ }^{* *} P<0.01$, ${ }^{* *} P<0.001$, and ${ }^{* * *} P<0.0001$, between the studied concentrations (unpaired $t$-test). $Q D$ Ag-In-Zn-S nanocrystals modified with: 11-mercaptoundecanoic acid (MUA), Cys L-cysteine, LA lipoic acid, FA folic acid, DOX doxorubicin

colonies was observed (Fig. 7). The statistical analyses also revealed significant differences $(P<0.05)$ among the compared groups. The greatest decrease in the number of colonies containing $2-10$ cells $(P<0.0001)$ was observed for QD-Cys-FA-DOX after treatment at a concentration of $25 \mu \mathrm{g} \cdot \mathrm{mL}^{-1}$ in comparison to $10 \mu \mathrm{g} \cdot \mathrm{mL}^{-1}$.

\section{In vitro scratch assay}

Cell migration is a multistep process which is fundamental to normal biological, as well as pathological, events such as cancer metastasis (Jonkman et al. 2014). In this study, an in vitro scratch assay was performed to determine the migratory/invasive potential of A549 cells after exposure to QD nanoconjugates. The principle of this method involves the determination of the time at which the artificial gap created by a tip is closed by the cells from the edge of the newly created gap. The rate of cell migration was estimated by comparing the images obtained at the beginning and at regular intervals during the migration of cells to close the scratch (Fig. 8).

The in vitro scratch assay revealed statistically significant inhibition $(P<0.05)$ of A549 cells after QD-MUA-FA-DOX treatment at $I C_{50}$ within 24 and $72 \mathrm{~h}$ postscratching in comparison to control (Fig. 9). The other studied QDs or free DOX did not reveal significant inhibition of cell migration compared to control. In previous studies, a considerable wound healing rate was observed by Sheng et al. for A549 cells treated with $1 \mu \mathrm{M}$ DOX $\left(0.54 \mu \mathrm{g} \cdot \mathrm{mL}^{-1}\right)$ at $24 \mathrm{~h}$ of incubation (Sheng et al. 2018) and by Li et al. for cells treated with $4 \mu \mathrm{g} \cdot \mathrm{mL}^{-1}$ DOX at $48 \mathrm{~h}$ of incubation (Li et al. 2019). 


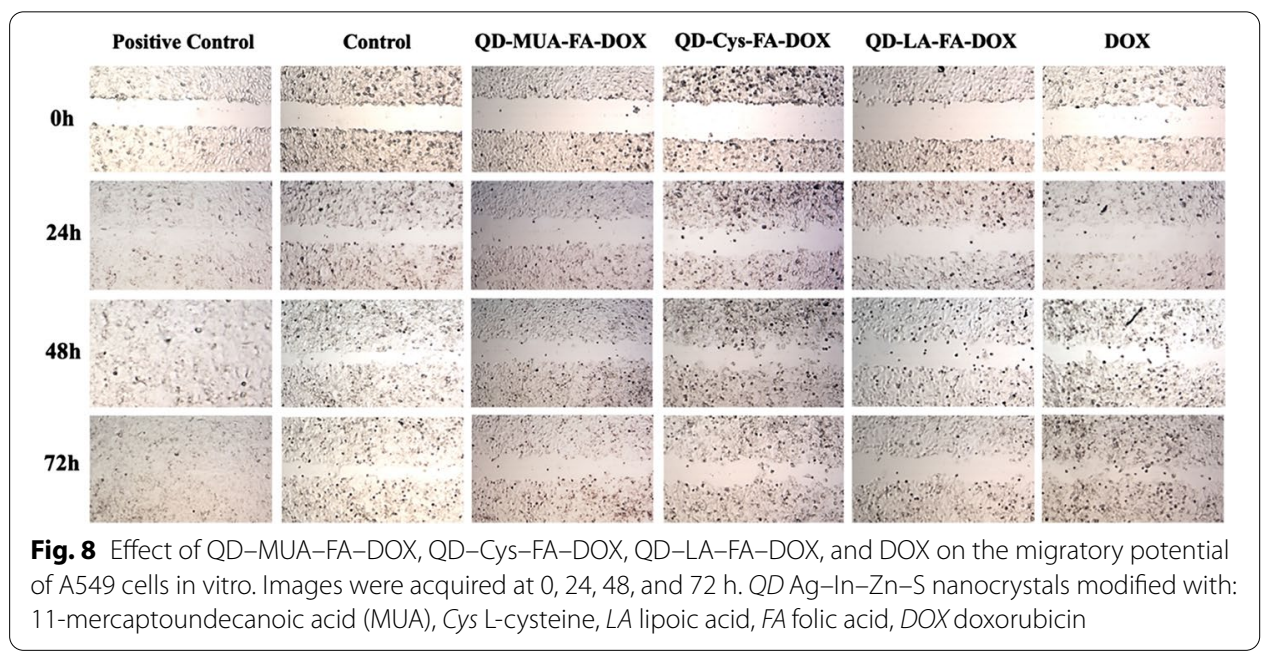

\section{Comet assay}

The comet assay was carried out to determine the genotoxicity of the as-synthesized QDFA-DOX nanoconjugates. This assay enables the detection of DNA damage in a single cell through the measurement of chromatin release during high-pH electrophoresis proceeded by exposure to lysis detergents and high amount of salts. The release of chromatin resembling comet structure is caused by genotoxic insult which is indicated by DNA strand breaks. The representative "comets" are counted under a fluorescence microscope which provides information about the DNA damage, estimated based on the intensity of the comet tail relative to the head (Collins et al. 2004; Stice et al. 2019). In this study, the in vitro comet assay was carried out on A549 cells treated with QD-MUA-FA-DOX, QD-Cys-FA-DOX, QD-LA-FA-DOX, or DOX as a reference, after $24 \mathrm{~h}$ of exposure. Statistically significant differences were observed in DNA damage between the cells treated with $I C_{50}$ and untreated control for all synthesized QD-FA-DOX nanoconjugates, but not for free DOX (Fig. 10). No difference from the control was observed for the compounds at the $I C_{10}$ concentration. The representative comets are shown in Fig. 11.

DOX is a well-known substrate of MDR protein, especially ABCB1 protein (also known as MDR1 protein) (Bosch et al. 1996; Takara et al. 2006). Since ABCB1 is a transmembrane protein, the extracellularly added DOX is exported directly from the vicinity of the outer membrane and thus does not even enter the cell interior (Takara et al. 2006). This likely explains the neglectable genotoxicity of free DOX, as the compound must reach the nucleus and DNA to exert its toxicity. On the other hand, FA present on the surface of nanoconjugates apparently dodges the action of ABCB1 protein by ligand-receptor interactions and enables DOX delivery to the cytoplasm. Moreover, FA-containing nanoconjugates might be able to deliver DOX to the cell nucleus, as proved for ultra-small gold nanoparticles conjugated with LA/FA/DOX complex (Dzwonek et al. 2018). Our results confirm this observation as the genotoxicity of FA/DOX-containing nanoconjugates was higher than the genotoxicity of free DOX. In addition, referring to the genotoxicity of QD-MUA-FA-DOX, its linker (MUA) alone was previously reported to be genotoxic at doses greater than or equal to $50 \mu \mathrm{g} \cdot \mathrm{mL}^{-1}$ within $2 \mathrm{~h}$ of treatment (Hoshino et al. 2004; Jamieson et al. 2007). 


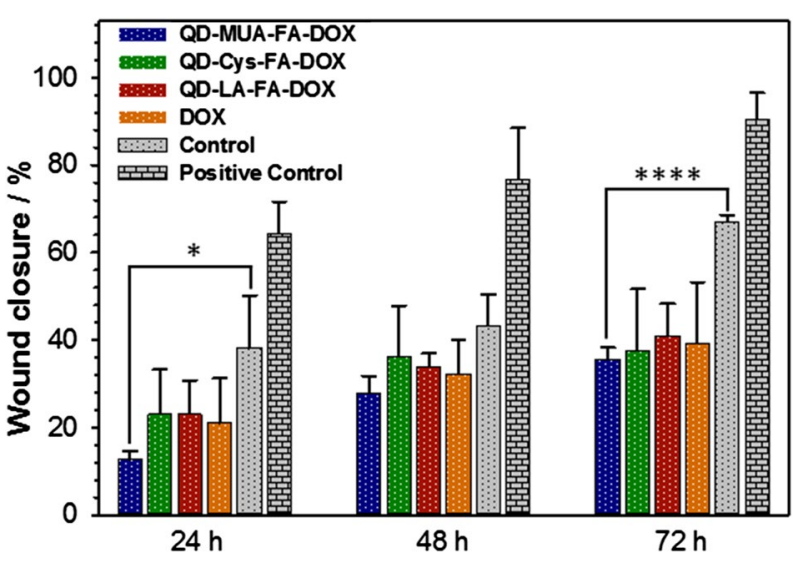

Fig. 9 Percentage of wound closure area plotted over time for QD-MUA-FA-DOX, QD-Cys-FA-DOX, QD-MUA-LA-DOX, and free DOX at the final $/ C_{50}$ concentration. Data were obtained from three independent experiments and presented as mean $\pm S D$. ${ }^{*} P<0.05$, ${ }^{* *} P<0.01$, ${ }^{* *} P<0.001$, and ${ }^{* * *} P<0.0001$, between the studied concentrations (unpaired $t$-test). $Q D$ Ag-In-Zn-S nanocrystals modified with: 11-mercaptoundecanoic acid (MUA), Cys L-cysteine, LA lipoic acid, FA folic acid, DOX doxorubicin

\section{Conclusions}

In this study, nanoconjugates of DOX and FA with Ag-In-Zn-S QDs modified with three different drug carriers (MUA, Cys, LA) were synthesized and characterized. The physicochemical properties of all QD nanocrystals, QD-FA nanocarriers, and QD-FADOX nanoconjugates were investigated using TEM, FTIR spectroscopy, DLS, ZP analysis, fluorescence spectroscopy, and UV-Vis spectroscopy. The TEM analyses enabled us to evaluate the size of QD nanocrystals, QD-FA nanocarriers, and QD-FA-DOX nanoconjugates, while the DLS analyses allowed establishing the hydrodynamic diameter of the as-synthesized QDs. The results from the FTIR spectroscopy evidenced the successful attachment of FA to QD nanocrystals and DOX to QD-FA nanocarriers. The conjugation of FA to QDs nanocrystals was also proven by fluorescence quenching of QDs. The UV-Vis analysis revealed the actual mass of FA and DOX covalently anchored to the surface of QD nanocrystals. The data obtained from the investigation of ZP demonstrated the smallest potential values for QD-Cys-FA-DOX, QD-MUAFA-DOX, and QD-LA-FA-DOX nanoconjugates indicating the favorable release of DOX from nanoconjugates in the cell medium. Among the three nanoconjugates, QDCys and QD-MUA nanocarriers were found to be attached to the highest amount of FA and DOX, with facilitated docking to FARs on adenocarcinomic human alveolar basal epithelial cells (A549) and providing more DOX into the cells. However, no such effect was found for the NIH/3T3 cells used as FAR-negative controls, indicating the targeted treatment of QD-MUA-FA-DOX against A549 lung cancer. The Alamar Blue cytotoxicity assay proved the above assumptions as the greatest cytotoxic effect was observed for QD-MUA-FA-DOX, QD-LA-FA-DOX, and QD-Cys-FA-DOX (QDs presented according to increasing $I C$ values). Among the nanoconjugates, QD-MUA-FA-DOX occurred to be the most cytotoxic against A549 cells, which may be explained by the mild cytotoxicity of MUA itself. In turn, the CFE assay revealed complete cell inhibition by all nanoconjugates at concentrations close to the $I C_{50}$ values determined by the Alamar Blue assay. The in vitro scratch assay also showed significant inhibition of 


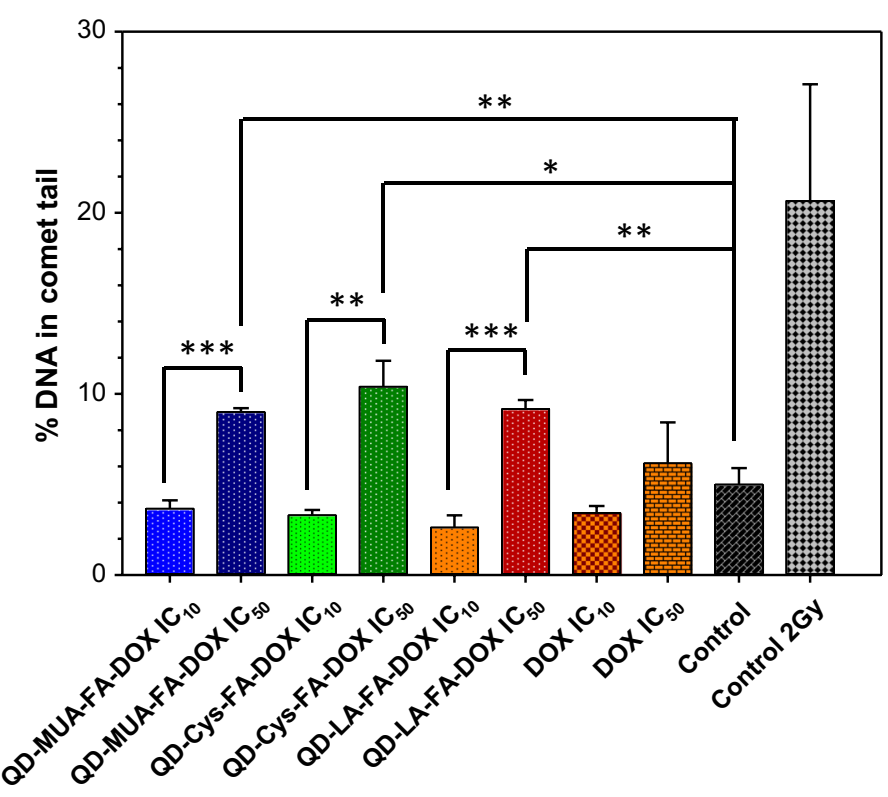

Fig. 10 Percent of DNA damage in A549 cells after treatment with QD-MUA-FA-DOX, QD-Cys-FA-DOX, QD-LA-FA-DOX, and DOX at $I C_{10}$ and $/ C_{50}{ }^{*} P<0.05$, ${ }^{* *} P<0.01$, ${ }^{* *} P<0.001$, and ${ }^{* * *} P<0.0001$, between the studied concentrations (unpaired $t$-test). Data were obtained from three independent experiments and presented as mean \pm SD. QD Ag-In-Zn-S nanocrystals modified with: 11-mercaptoundecanoic acid (MUA), Cys L-cysteine, LA lipoic acid, FA folic acid, DOX doxorubicin

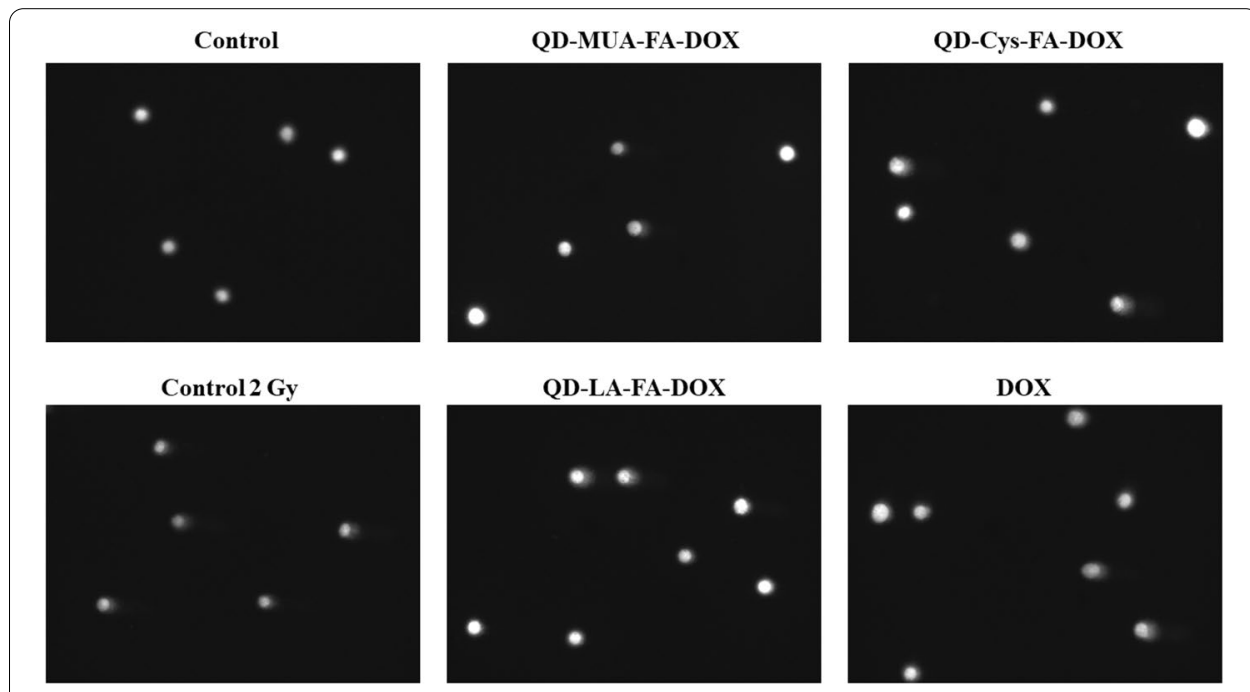

Fig. 11 DNA damage of A549 cells after $24 \mathrm{~h}$ of treatment with the compounds at $/ C_{50}$, detected by the comet assay. Images were obtained from a fluorescent microscope. QD Ag-In-Zn-S nanocrystals modified with: 11-mercaptoundecanoic acid (MUA), Cys L-cysteine, LA lipoic acid, FA folic acid, DOX doxorubicin

A549 cell migration, only for treatment with QD-MUA-FA-DOX at $I C_{50}$. On the other hand, the comet test demonstrated significant genotoxicity of all QD nanoconjugates at concentrations close to $I C_{50}$. A higher genotoxicity was also observed for free DOX at $I C_{50}$; however, it was not statistically significant, suggesting the higher genotoxicity of 
FA/DOX-containing nanoconjugates than that of DOX alone. Thus, the proposed QDs can perfectly fulfill their role in the targeted delivery of DOX to lung cancer A549 cells, which are well designed for preclinical animal studies.

\section{Supplementary Information}

The online version contains supplementary material available at https://doi.org/10.1186/s12645-021-00077-9.

\section{Additional file 1}

\section{Abbreviations}

CFE: Colony forming efficiency assay; Cys: L-Cysteine; DDT: 1-Dodecanethiol; DLS: Dynamic light scattering; DMSO: Dimethyl sulfoxide; DOX: Doxorubicin; EDC: N-(3-Dimethylaminopropyl)-N'-ethylcarbodiimide hydrochloride; FA: Folic acid; FAR: Folate receptor; FBS: Fetal bovine serum; FTIR: Fourier transformation infrared spectroscopy; $/ C_{50}$ : Half-maximal inhibitory concentration; LA: Lipoic acid; MDR: Multidrug resistance; MPA: 3-Mercaptopropionic acid; MUA: 11-Mercaptoundecanoic acid; NHS: N-Hydroxy-succinimide; ODE: 1-Octadecene; OLA: Oleylamine; PBS: Phosphate-buffered saline; PDI: Polydispersity index; PL: Maximum of the photoluminescence band; QD: Quantum dot; Q.Y.: Photoluminescence quantum yield; TDD: Targeted drug delivery; TEM: Transmission electron microscopy; ZP: Zeta potential.

\section{Acknowledgments}

The authors are grateful to Zuzanna Wichrzycka for help in organizing the CFE assay and wound healing experiment. This work was implemented as a part of Operational Project Knowledge Education Development 2014-2020, co-financed by the European Social Fund, Project No. POWR.03.02.00-00-I007/16-00 (POWER 2014-2020).

\section{Author contributions}

MR performed the biological research, analyzed and interpreted the final results, and was a major contributor in writing the manuscript. PK synthesized the QD nanocrystals, and performed the fluorescence experiments and analyzed the results. AK synthesized the QD-FA and QD-FA-DOX nanoconjugates, performed the FTIR experiments and analyzed the results, and participated in writing the original draft. PB designed and supervised the QD synthesis and photoluminescence experiments, and participated in writing the original draft. AMN designed and reviewed the chemical part of the experiments, performed the DLS and ZP experiments and analyzed the results, performed the quantitative analysis of the QD-FA nanocarriers and QD-FA-DOX nanoconjugates, and wrote the manuscript. MW performed the comet assay and wrote the manuscript. MK analyzed and interpreted the biological data and participated in writing the original draft. IPG analyzed and interpreted the final results and discussion. All the authors read and approved the final manuscript.

\section{Funding}

Not applicable.

\section{Availability of data and material}

The datasets used and/or analyzed during this study are available from the corresponding author on reasonable request.

\section{Ethics approval and consent to participate}

Not applicable.

\section{Consent for publication}

Not applicable.

\section{Competing interests}

There are no conflicts to declare.

\section{Author details}

${ }^{1}$ Faculty of Pharmacy, Medical University of Warsaw, Banacha 1, 02-097 Warsaw, Poland. ${ }^{2}$ Faculty of Chemistry, University of Warsaw, Pasteura 1, 02-093 Warsaw, Poland. ${ }^{3}$ Faculty of Chemistry, Warsaw University of Technology, Noakowskiego 3, 00-664 Warsaw, Poland. ${ }^{4}$ Centre for Radiobiology and Biological Dosimetry, Institute of Nuclear Chemistry and Technology, Dorodna 16, 03-195 Warsaw, Poland. ${ }^{5}$ Department of Medical Biology and Translational Research, Institute of Rural Health, Jaczewskiego 2, 20-090 Lublin, Poland.

Received: 26 August 2020 Accepted: 22 January 2021

Published online: 08 February 2021

\section{References}

Abbasi E, Kafshdooz T, Bakhtiary M, Nikzamir N, Nikzamir N, Nikzamir M, et al. Biomedical and biological applications of quantum dots. Artif Cells Nanomed Biotechnol. 2016;44(3):885-91.

Abdelhameed M, Martir DR, Chen S, Xu WZ, Oyeneye OO, Chakrabarti S, Zysman-Colman E, Charpentier PA. Tuning the optical properties of silicon quantum dots via surface functionalization with conjugated aromatic fluorophores. Sci Rep. 2018;8(1):3050.

Ali O, Zayed D, Ramadan W, Kamel OA, Shehab M, Ebrahim S. Synthesis, characterization and cytotoxicity of polyethylene glycol-encapsulated CdTe quantum dots. Int Nano Lett. 2019;9(1):61-71. 
American Cancer Society. Key statistics for lung cancer. https:/www.cancer.org/cancer/lung-cancer/about/key-statistics .html. Accessed 04 Jan 2021.

Araghi S, Kiefte-de Jong JC, Van Dijk SC, Swart KMA, Van Laarhoven HW, Van Schoor NM, De Groot LCPGM, Lemmens V, Stricker BH, Uitterlinden AG, Van Der Velde N. Folic acid and vitamin B12 supplementation and the risk of cancer long-term follow-up of the B vitamins for the prevention of osteoporotic fractures (B-PROOF) trial. Cancer Epidemiol Biomark Prev. 2019;28(2):275-82.

Albanese A, Tang PS, Chan WCW. The effect of nanoparticle size, shape, and surface chemistry on biological systems. Ann Rev Biomed Eng. 2012;14:1-16.

Au KM, Balhorn R, Balhorn MC, Park SI, Wang AZ. High-performance concurrent chemo-immuno-radiotherapy for the treatment of hematologic cancer through selective high-affinity ligand antibody mimic-functionalized doxorubicinencapsulated nanoparticles. ACS Central Sci. 2019;5(1):122-44.

Aydemir D, Hashemkhani M, Acar HY, Ulusu NN. Evaluation of the biocompatibility of the GSH-coated Ag2S quantum dots in vitro: a perfect example for the non-toxic optical probes. Mol Biol Rep. 2020;47(6):4117-29.

Bajwa N, Mehra NK, Jain K, Jain NK. Targeted anticancer drug delivery through anthracycline antibiotic bearing functionalized quantum dots. Artif Cells Nanomed Biotechnol. 2016;44(7):1774-82.

Barba-Vicente V, Parra MJA, Boyero-Benito JF, Auría-Soro C, Juanes-Velasco P, Landeira-Viñuela A, Furones-Cuadrado Á, Hernández Á-P, Manzano-Román R, Fuentes M. Detection of human P53 in-vitro expressed in a transcriptiontranslation cell-free system by a novel conjugate based on cadmium sulphide nanoparticles. Nanomaterials. 2020;10(5):984.

Bendale Y, Bendale V, Paul S. Evaluation of cytotoxic activity of platinum nanoparticles against normal and cancer cells and its anticancer potential through induction of apoptosis. Integ Med Res. 2017;6(2):141-8.

Bilan R, Fleury F, Nabiev I, Sukhanova A. Quantum dot surface chemistry and functionalization for cell targeting and imaging. Bioconjug Chem. 2015;26(4):609-24.

Bosch I, Croop J. P-glycoprotein multidrug resistance and cancer. Biochim Biophys Acta (BBA) Rev Cancer. 1996;1288(2):37-54

Cao X, Zhang Q, Zhang C, Li Z, Zheng W, Liu M, Wang B, Huang S, Li L, Huang X, Kong L. A novel approach to coat silica on quantum dots Forcing decomposition of tetraethyl orthosilicate in toluene at high temperature. J Alloys Compounds. 2020;817:152698.

Coates J. In: Meyers RA, editor. Encyclopedia of analytical chemistry. Chichester: Wiley; 2000. p. 10815-73. https://doi. org/10.1002/9780470027318.a5606.

Collins AR. The comet assay for DNA damage and repair: principles, applications, and limitations. Mol Biotechnol. 2004;26(3):249-61.

Chauhan VP, Stylianopoulos T, Martin JD, Popović Z, Chen O, Walid S, et al. Normalization of tumour blood vessels improves the delivery of nanomedicines in a size-dependent manner. Nat Nanotechnol. 2012;7:383-8.

Derfus AM, Chan WC, Bhatia SN. Probing the cytotoxicity of semiconductor quantum dots. Nano Lett. 2003;4:11-8.

Dubertret B, Skourides P, Norris DJ, Noireaux V, Brivanlou AH, Libchaber A. In vivo imaging of quantum dots encapsulated in phospholipid micelles. Science. 2002;298:1759-62.

Duman FD, Erkisa M, Khodadust R, Ari F, Ulukaya E, Acar HY. Folic acid-conjugated cationic $\mathrm{Ag}_{2} \mathrm{~S}$ quantum dots for optical imaging and selective doxorubicin delivery to HeLa cells. Nanomedicine (Lond). 2017;12(19):2319-33.

Dzwonek M, Załubiniak D, Piątek P, Cichowicz G, Męczynska-Wielgosz S, Stępkowski T, et al. Towards potent but less toxic nanopharmaceuticals_lipoic acid bioconjugates of ultrasmall gold nanoparticles with an anticancer drug and addressing unit. RSC Adv. 2018;8(27):14947-57.

Elkhodiry MA, Husseini GA, Velluto D. Targeting the folate receptor: effects of conjugating folic acid to DOX loaded polymeric micelles. Anticancer Agents Med Chem. 2016;16(10):1275-80.

European Cancer Information System. Incidence and mortality estimates 2020. https://ecis.jrc.ec.europa.eu/index.php. Accessed 04 Jan 2021.

Gabka G, Bujak P, Giedyk K, Ostrowski A, Malinowska K, Herbich J, et al. A simple route to alloyed quaternary nanocrystals $\mathrm{Ag}-\mathrm{In}-\mathrm{Zn}-\mathrm{S}$ with shape and size control. Inorg Chem. 2014;53(10):5002-12.

Gabka G, Bujak P, Kotwica K, Ostrowski A, Lisowski W, Sobczak JW, et al. Luminophores of tunable colors from ternary $\mathrm{Ag}-\mathrm{In}-\mathrm{S}$ and quaternary Ag-In-Zn-S nanocrystals covering the visible to near-infrared spectral range. Phys Chem Chem Phys. 2017;19(2):1217-28.

Gao X, Yang L, Petros JA, Marshall FF, Simons JW, Nie S. In vivo molecular and cellular imaging with quantum dots. Curr Opin Biotechnol. 2005;16:63-72.

Gerion D, Pinaud F, Williams SC, Parak WJ, Zanchet D, Weiss S, et al. Synthesis and properties of biocompatible watersoluble silica-coated CdSe/ZnS semiconductor quantum dots. J Phys Chem B. 2001:105:8861-71.

Gu Y-J, Cheng J, Man CW-Y, Wong W-T, Cheng SH. Gold-doxorubicin nanoconjugates for overcoming multidrug resistance. Nanomed Nanotechnol Biol Med. 2012;8(2):204-11.

Ha SW, Weiss D, Weitzmann MN, Beck GR. In: Subramani K, Ahmed W, editors. Nanobiomaterials in clinical dentistry. 2nd ed. Amsterdam: Elsevier; 2019. p. 77-112. https://doi.org/10.1016/B978-0-12-815886-9.00004-8.

Hardman R. A toxicologic review of quantum dots: toxicity depends on physicochemical and environmental factors. Environ Health Perspect. 2006;114(2):165-72.

Hobbs SK, Monsky WL, Yuan F, Roberts WG, Griffith L, Torchilin VP, et al. Regulation of transport pathways in tumor vessels: role of tumor type and microenvironment. Proc Natl Acad Sci USA. 1998;95:4607-12.

Hong $Y$, Che S, Hui B, Yang Y, Wang X, Zhang $X$, et al. Lung cancer therapy using doxorubicin and curcumin combination: targeted prodrug based, pH sensitive nanomedicine. Biomed Pharmacother. 2019;112:108614.

Hoshino A, Fujioka K, Oku T, Suga M, Sasaki YF, Ohta T, et al. Physicochemical properties and cellular toxicity of nanocrystal quantum dots depend on their surface modification. Nano Lett. 2004;4(11):2163-9.

Hu X, Gao X. Silica-polymer dual layer-encapsulated quantum dots with remarkable stability. ACS Nano. 2010;4(10):6080-6.

Hussain N, Jaitley V, Florence AT. Recent advances in the understanding of uptake of microparticulates across the gastrointestinal lymphatics. Adv Drug Delivery Rev. 2001;50:107-42. 
Jamieson T, Bakhshi R, Petrova D, Pocock R, Imani M, Seifalian AM. Biological applications of quantum dots. Biomaterials. 2007;28(31):4717-32.

Jin K-T, Lu Z-B, Chen J-Y, Liu Y-Y, Lan H-R, Dong H-Y, et al. Recent trends in nanocarrier-based targeted chemotherapy: selective delivery of anticancer drugs for effective lung, colon, cervical, and breast cancer treatment. J Nanomaterials. 2020. https://doi.org/10.1155/2020/9184284.

Jonkman JE, Cathcart JA, Xu F, Bartolini ME, Amon JE, Stevens KM, et al. An introduction to the wound healing assay using live-cell microscopy. Cell Adhes Migr. 2014;8(5):440-51.

Jung K, Rezska R. Mitochondria as subcellular targets for clinically useful anthracyclines. Adv Drug Deliv Rev. 2001:49:87-105.

Kaaki K, Hervé-Aubert K, Chiper M, Shkilnyy A, Soucé M, Benoit R, et al. Magnetic nanocarriers of doxorubicin coated with poly(ethylene glycol) and folic acid: relation between coating structure, surface properties, colloidal stability, and cancer cell targeting. Langmuir. 2012;28(2):1496-505.

Kanwal U, Bukhari NI, Rana NF, Rehman M, Hussain K, Abbas N, et al. Doxorubicin-loaded quaternary ammonium palmitoyl glycol chitosan polymeric nanoformulation: uptake by cells and organs. Int J Nanomed. 2019;14:1-15.

Kharkar PS, Soni G, Rathod V, Shetty S, Gupta MK, Yadav KS. An outlook on procedures of conjugating folate to (co)polymers and drugs for effective cancer targeting. Drug Dev Res. 2020;81(7):1-14.

Kumar P, Huo P, Liu B. Formulation strategies for folate-targeted liposomes and their biomedical applications. Pharmaceutics. 2019;11(8):381.

Kumar A, White J, James Christie R, Dimasi N, Gao C. In: Goodnow RA, editor. Annual reports in medicinal chemistry, vol. 50. Amsterdam: Academic Press; 2017. p. 441-80.

Lakowicz JR. Principles of fluorescence spectroscopy. Baltimore: Springer; 2010.

Li L, He S, Yu L, Elshazly EH, Wang H, Chen K, et al. Codelivery of DOX and siRNA by folate-biotin-quaternized starch nanoparticles for promoting synergistic suppression of human lung cancer cells. Drug Deliv. 2019;26(1):499-508.

Li N, Ma Y, Yang C, Guo L, Yang X. Interaction of anticancer drug mitoxantrone with DNA analyzed by electrochemical and spectroscopic methods. Biophys Chem. 2005;116(3):199-205.

Li Z, Tan S, Li S, Shen Q, Wang K. Cancer drug delivery in the nano era: an overview and perspectives (Review). Oncol Rep. 2017;38:611-24.

Liang CC, Park AY, Guan JL. In vitro scratch assay: a convenient and inexpensive method for analysis of cell migration in vitro. Nat Protoc. 2007;2(2):329-33.

Lin Y-Q, Zhang J, Liu S-J, Ye H. Doxorubicin loaded silica nanoparticles with dual modification as a tumor-targeted drug delivery system for colon cancer therapy. J Nanosci Nanotechnol. 2018;18(4):2330-6.

Lovitt CJ, Shelper TB, Avery VM. Doxorubicin resistance in breast cancer cells is mediated by extracellular matrix proteins. BMC Cancer. 2018;18(1):41.

Maghsoudnia N, Eftekhari RB, Sohi AN, Zamzami A, Dorkoosh FA. Application of nano-based systems for drug delivery and targeting: a review. J Nanopart Res. 2020;22:245.

Matea CT, Mocan T, Tabaran F, Pop T, Mosteanu O, Puia C, et al. Quantum dots in imaging, drug delivery and sensor applications. Int J Nanomed. 2017;12:5421-31.

Michalet X, Pinaud FF, Bentolila LA, Tsay JM, Doose S, Li JJ, et al. Quantum dots for live cells, in vivo imaging, and diagnostics. Science. 2005;307:538-44.

Oliai Araghi S, Kiefte-de Jong JC, van Dijk SC, Swart KMA, van Laarhoven HW, van Schoor NM, et al. Folic acid and vitamin B12 supplementation and the risk of cancer: long-term follow-up of the B vitamins for the prevention of osteoporotic fractures (B-PROOF) trial. Cancer Epidemiol Biomark Prev. 2019;28(2):275-82.

Olsztynska S, Komorowska M. Biomedical engineering: trends research and technologies. Lodon: IntechOpen; 2011.

Patel NR, Piroyan A, Ganta S, Morse AB, Candiloro KM, Solon AL, et al. In vitro and in vivo evaluation of a novel folate-targeted theranostic nanoemulsion of docetaxel for imaging and improved anticancer activity against ovarian cancers. Cancer Biol Ther. 2018;19(7):554-64.

Peretz V, Motiei M, Sukenik CN, Popovtzer R. The effect of nanoparticle size on cellular binding probability. J Atom Mol Opt Phys. 2012;2012:1-7.

Petersen LF, Brockton NT, Bakkar A, Liu S, Wen J, Weljie AM, et al. Elevated physiological levels of folic acid can increase in vitro growth and invasiveness of prostate cancer cells. BJU Int. 2012;109(5):788-95.

Peynshaert K, Soenen SJ, Manshian BB, Doak SH, Braeckmans K, De Smedt SC, et al. Coating of quantum dots strongly defines their effect on lysosomal health and autophagy. Acta Biomater. 2017;48:195-205.

Pieroth R, Paver S, Day S, Lammersfeld C. Folate and its impact on cancer risk. Curr Nutr Rep. 2018;7(3):70-84.

Pilch J, Matysiak-Brynda E, Kowalczyk A, Bujak P, Mazerska Z, Nowicka AM, et al. New unsymmetrical bisacridine derivatives noncovalently attached to quaternary quantum dots improve cancer therapy by enhancing cytotoxicity toward cancer cells and protecting normal cells. ACS Appl Mater Interfaces. 2020;12(15):17276-89.

Ponti J, Kinsner-Ovaskainen A, Norlén H, Altmeyer S, Andreoli C, Bogni A, Chevillard S, De Angelis I, Chung S-T, Fujita K, Eom I, Gilliland D, Grollino M, Gulumian M, Hirsch C, Ichiraku K, Igarashi T, Jeong J, Jo E, Kim D-Y, Kaiser J-P, Lagache D, La Spina R, Lee JK, Lee J, Lovera A, Mäder-Althaus X, Nesslany F, Jimenez IO, Pacchierotti F, Pianella F, Paget V, Kim TR, Roszak J, Rosenkranz P, Simar S, Stępnik M, Vetten M, Woong Song N, Yang J-Y, Rossi F. Interlaboratory comparison study of the Colony Forming Efficiency assay for assessing cytotoxicity of nanomaterials. JRC science and policy reports. Report EUR 27009 EN. European Commission. Luxembourg: Publications Office of the European Union; 2014. p. 1-80.

Pyle AM, Rehmann JP, Meshoyrer R, Kumar CV, Turro NJ, Barton JK. Mixed-ligand complexes of ruthenium(II): factors governing binding to DNA. J Am Chem Soc. 1989;111(8):3051-8.

Qian F, Li X, Tang L, Lai SK, Lu C, Lau SP. Potassium doping: Tuning the optical properties of graphene quantum dots. AIP Adv. 2016;6(7):075116.

Qian Z, Ma J, Shan X, Shao L, Zhou J, Chen J, Feng H. Surface functionalization of graphene quantum dots with small organic molecules from photoluminescence modulation to bioimaging applications: an experimental and theoretical investigation. RSC Adv. 2013;3(34):14571-9. 
Qiu L, Bi Y, Wang C, Li J, Guo P, Li J, He W, Wang J, Jiang P. Protein a detection based on quantum dots-antibody bioprobe using fluorescence coupled capillary electrophoresis. Int J Mol Sci. 2014;15(2):1804-11.

Sahoo SL, Liu C-H, Kumari M, Wu W-C, Wang C-C. Biocompatible quantum dot-antibody conjugate for cell imaging, targeting and fluorometric immunoassay: crosslinking, characterization and applications. RSC Advances. 2019;9(56):32791-803.

Salahuddin N, Galal A. In: Ficai A, Grumezescu AM, editors. Nanostructures for cancer therapy. Amsterdam: Elsevier; 2017. p. 87-128. https://doi.org/10.1016/B978-0-323-46144-3.00004-0.

Sheng W, Mao H, Wang C, Yang N, Zhang Z, Han J. Dehydrocostus lactone enhances chemotherapeutic potential of doxorubicin in lung cancer by inducing cell death and limiting metastasis. Med Sci Monit Int Med J Exp Clin Res. 2018;24:7850-61.

Siegel RL, Miller KD, Jemal A. Cancer statistics, 2020. Cancer J Clin. 2020;70(1):7-30

Silverman JA, Deitcher SR. Marqibo ${ }^{\circledR}$ (vincristine sulfate liposome injection) improves the pharmacokinetics and pharmacodynamics of vincristine. Cancer Chemother Pharmacol. 2013;71:555-64.

Sosnik A. Chapter 1 from the "Magic Bullet" to advanced nanomaterials for active targeting in diagnostics and therapeutics. In: Sarmento B, Das Neves J, editors. Biomedical applications of functionalized nanomaterials. Amsterdam: Elsevier; 2018. p. 1-32.

Stanishevsky AV, Styres C, Yockell-Lelievre H, Yusuf N. Nanostructured carbon beads-properties and biomedical applications. J Nanosci Nanotechnol. 2011;11(10):8705-11.

Stice SA, Beedanagari SR, Vulimiri SV, Bhatia SP, Mahadevan B. In: Gupta RC, editor. Biomarkers in toxicology. 2nd ed. London: Academic Press; 2019. p. 807-21. https://doi.org/10.1016/B978-0-12-814655-2.00044-X.

Susumu K, Mei BC, Mattoussi H. Multifunctional ligands based on dihydrolipoic acid and polyethylene glycol to promote biocompatibility of quantum dots. Nat Protoc. 2009:4(3):424-36.

Takara K, Sakaeda T, Okumura K. An update on overcoming MDR1-mediated multidrug resistance in cancer chemotherapy. Curr Pharm Des. 2006;12(3):273-86.

Thomas GJ Jr, Kyogoku Y. In: Brame EG, Grasselli JG, editors. Infrared and Raman spectroscopy, Part C, vol. 1. New York: Marcel Dekker Inc; 1977. p. 717-872.

Verma J, Lal S, Van Noorden CJ. Inorganic nanoparticles for the theranostics of cancer. Eur J Nanomed. 2015;7:271-87.

Wakharde AA, Awad AH, Bhagat A, Karuppayil SM. Synergistic activation of doxorubicin against cancer: a review. Am J Clin Microbiol Antimicrob. 2018;1(2):1009.

Wegner KD, Hildebrandt N. Quantum dots: bright and versatile in vitro and in vivo fluorescence imaging biosensors. Chem Soc Rev. 2015;44(14):4792-834.

Xu C, Wang Y, Guo Z, Chen J, Lin L, Wu J, et al. Pulmonary delivery by exploiting doxorubicin and cisplatin co-loaded nanoparticles for metastatic lung cancer therapy. J Control Release. 2019;295:153-63.

Yuan M, Huang L-L, Chen J-H, Wu J, Xu Q. The emerging treatment landscape of targeted therapy in non-small-cell lung cancer. Signal Transduct Target Ther. 2019;4(1):61.

Yue PY, Leung EP, Mak NK, Wong RN. J Biomol Screen. 2010;15:427.

Zhang J, Rana S, Srivastava RS, Misra RDK. On the chemical synthesis and drug delivery response of folate receptor-activated, polyethylene glycol-functionalized magnetite nanoparticles. Acta Biomater. 2008;4(1):40-8.

Zhang J, Zhao X, Xian M, Dong C, Shuang S. Folic acid-conjugated green luminescent carbon dots as a nanoprobe for identifying folate receptor-positive cancer cells. Talanta. 2018;183:39-47.

Zhao S, Sun S, Jiang K, Wang Y, Liu Y, Wu S, et al. In situ synthesis of fluorescent mesoporous silica-carbon dot nanohybrids featuring folate receptor-overexpressing cancer cell targeting and drug delivery. Nano-Micro Lett. 2019;11:32.

Zhong W, Yu JS, Huang W, Ni K, Liang Y. Spectroscopic studies of interaction of chlorobenzylidine with DNA. Biopolymers. 2001;62(6):315-23.

Zhou J, Liu Y, Tang J, Tang W. Surface ligands engineering of semiconductor quantum dots for chemosensory and biological applications. Mater Today. 2017;20(7):360-76.

\section{Publisher's Note}

Springer Nature remains neutral with regard to jurisdictional claims in published maps and institutional affiliations.

Ready to submit your research? Choose BMC and benefit from:

- fast, convenient online submission

- thorough peer review by experienced researchers in your field

- rapid publication on acceptance

- support for research data, including large and complex data types

- gold Open Access which fosters wider collaboration and increased citations

- maximum visibility for your research: over 100M website views per year

At BMC, research is always in progress.

Learn more biomedcentral.com/submissions 